\title{
Entrainment of Air into a Balcony Spill Plume
}

\author{
ROGER HARRISON $^{1, *}$ AND MICHAEL SPEARPOINT ${ }^{2}$ \\ ${ }^{1}$ BRE Fire and Security (incorporating the Fire Research Station [FRS]), BRE, \\ Watford, WD25 9XX, UK. \\ ${ }^{2}$ Department of Civil Engineering, University of Canterbury, New Zealand.
}

\begin{abstract}
This paper examines various uncertainties relating to calculation methods for the balcony spill plume. The approach of physical scale modelling was used in the analysis. Comparisons are made between the experimental results and the predictions made using these calculation methods. This work has demonstrated that the presence of a downstand at the spill edge of a compartment opening appears to have little effect on the entrainment of air into the subsequent spill plume. A simplified spill plume formula has also been developed to predict the mass flow rate of gases, which inherently includes entrainment of air into the free ends.
\end{abstract}

KEY WORDS: balcony spill plume, downstand, smoke ventilation, entrainment.

\section{INTRODUCTION}

Currently, there are several calculation methods available to designers of smoke and heat exhaust ventilation systems (SHEVS) for atrium buildings involving the balcony spill plume illustrated in Figure 1. These include the BRE spill plume method [1] and various simplified spill plume formulae (i.e. a single line equation). These methods are important to the designer in order to calculate the required exhaust fan capacity or vent area for a SHEVS. However, there is some controversy over the accuracy and robustness of some of these design formulae for spill plumes. There are limitations to the available calculation methods and there are also areas of uncertainty which require further research. This paper is a summary of an experimental study [2] examining two areas of uncertainty involving spill plume calculations which are described below:

- Simplified spill plume formulae were initially developed by Law [3] and Thomas [4] in order to ease the task of the designers of SHEVS. They used data for spill plumes with free ends, thus including edge entrainment. However, more recent studies by Poreh et al [5], using data without free ends and Thomas et al [6] using data both without and with free ends, provide simplified formulae with a more robust basis. This work aims to provide a simplified formula to include entrainment into the free ends of the spill plume using new experimental data and existing correlation methods. It should be noted that the more complicated BRE spill plume method provides the option to include entrainment of air into the free ends of the plume.

\footnotetext{
* Author for correspondence harrisonr@bre.co.uk Tel: +44 (0)1923 664972 Fax:+44 (0)1923 664910
} 
- The majority of spill plume calculation methods are based on experimental or theoretical studies in which the approach flow is from a compartment with a flat ceiling at the spill edge. A common scenario at the spill edge of a compartment opening is the presence of a downstand as illustrated in Figure 2. No current simplified spill plume formulae apply to flows with a downstand at the balcony spill edge. There is also a lack of relevant experimental data for this scenario. This work aims to develop a robust simplified spill plume formula when a downstand exists at the edge of the balcony, using existing correlation methods. It should be noted that the BRE spill plume method includes the option of a downstand at the balcony edge in the calculation. However, this scenario has never been validated experimentally.

In general, the objective of this work is to address various uncertainties in spill plume calculations in order to improve the available guidance. The work aims to provide robust, validated and relevant simplified formulae to enable more accurate calculations involving the spill plume in smoke ventilation design.

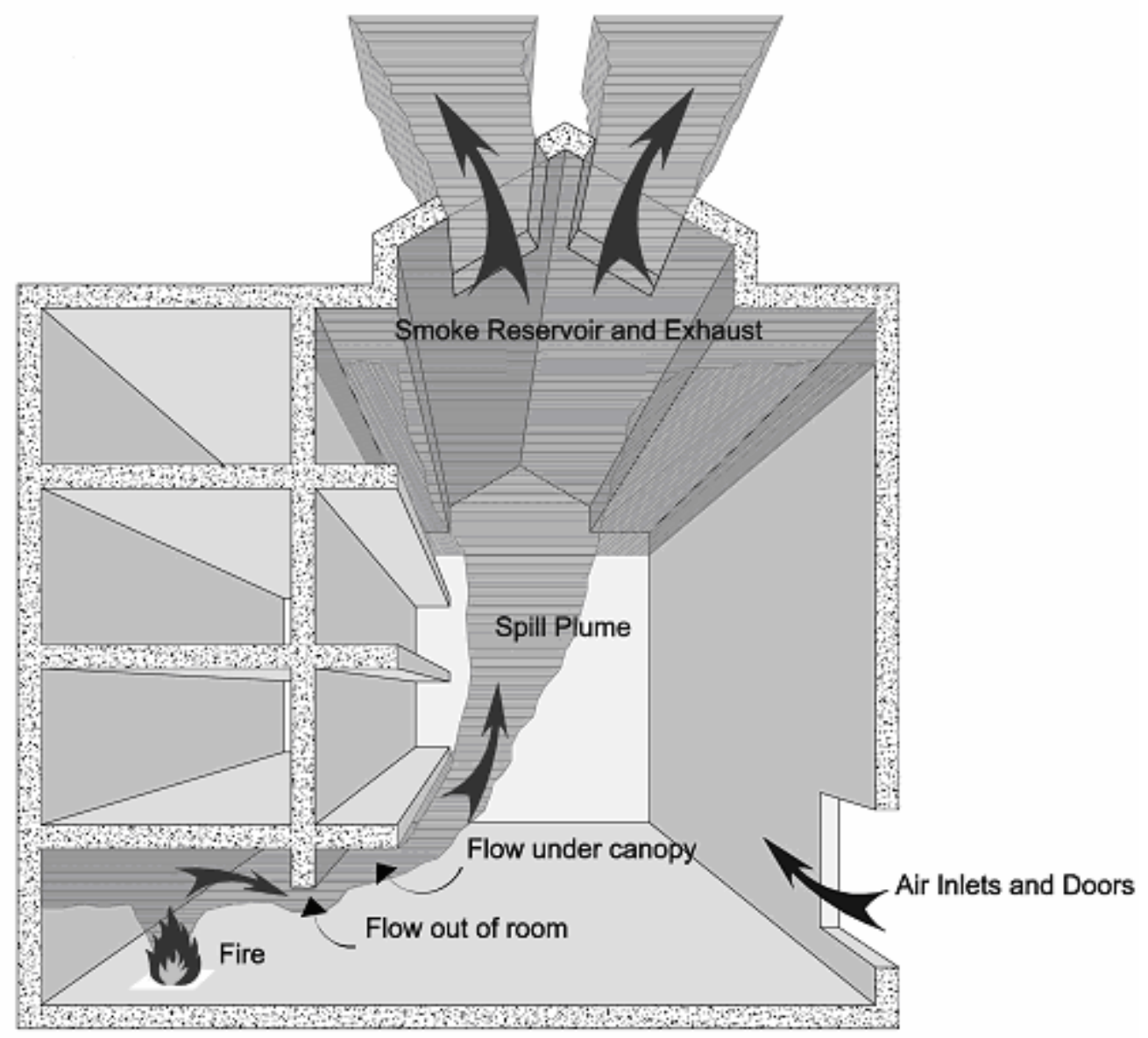

Figure 1: A SHEVS with a typical balcony spill plume [adapted from an original, courtesy of NV IFSET SA] 


\section{THE BRE SPILL PLUME METHOD}

Morgan and Marshall [7,8] of the Building Research Establishment (BRE) in the UK first developed the BRE spill plume method. Modifications have subsequently been made to extend the method to apply to adhered spill plumes, and to update aspects of the horizontal flow from a compartment opening $[9,10]$.

The BRE spill plume method is complicated and the calculation procedure is not fully reproduced herein. For full details of the calculation procedure, reference should be made to the original papers by Morgan and Marshall [7,8] and the current design document detailing a user guide to this calculation method [1].

The calculation method deals with the spill plume in three discrete regions:

1. The horizontally flowing buoyant layer of smoky gases approaching the spill edge (i.e. the approach flow).

2. The 'rotation' region, as the horizontally moving layer rotates around the spill edge (i.e. as the gases change from a horizontally moving flow to a vertically moving flow).

3. The vertically moving smoke flow in the form of a two dimensional line plume.

There is a specific dependence on calculating variables of the approach flow of a horizontally flowing thermal buoyant layer toward an opening, through which the gases then rise. Two key variables of the approach flow must initially be determined, for example, the depth of the layer and the temperature of the layer at its highest point. The remaining approach flow parameters can then be calculated using a theory to describe the horizontal flow of buoyant gases toward an opening by Morgan [10]. The mass flow rate of gases at the opening can be determined using Equation 1.

$$
M_{w}=\frac{2}{3} C_{d}^{3 / 2}\left(2 g \theta_{c, w} T_{1}\right)^{1 / 2} \frac{W \rho_{1}}{T_{c, w}} d_{w}^{3 / 2} \kappa_{M}
$$

The amount of air entrainment into the gases which rotate around the spill edge can then be determined using Equation 2.

$$
\delta m=\frac{2}{3} \rho_{1} W \alpha^{\prime}\left(\frac{2 g \theta_{c, w}}{T_{1}}\right) d_{w}^{3 / 2}
$$

Morgan and Hansell [9] empirically derived the entrainment constant $(\alpha$ ) in the rotation region to be 1.1, updating the original value of 0.9 found by Morgan and Marshall [7]. Morgan and Hansell recognised that this high value for $\alpha$ infers an anomalously large amount of entrainment into the rotating flow of gases at the spill edge. This large value of $\alpha^{\prime}$ is a result of treating all anomalous entrainment above the spill edge as if it occurred in the rotation region [1]. This aspect of the BRE spill plume method has led to some controversy and debate. Subsequent work by Miles et al [11] and Yii [12] indicate only a small degree of entrainment into the rotation 
region. However, the BRE spill plume method is recognised to be empirical in nature, with the overall calculation package adjusted to provide good agreement with experimental results [9].

The mass flow rate of gases rising in a vertical flow past the spill edge $\left(M_{y}\right)$ is given by Equation 3. This is used in the subsequent analysis of entrainment of air into the vertically rising plume.

$M_{y}=\delta m+M_{w}$

Morgan and Marshall utilised the theory of Lee and Emmons [13] in the calculation of a virtual 'Equivalent Gaussian Source' (EGS) in the horizontal plane. The EGS provides the source of the vertically rising thermal plume at the spill edge. This plume is a two dimensional line plume rising from a 'retarded source' [7,13]. Morgan and Marshall modified the Lee and Emmons approach to determine the source parameters of the EGS from the approach flow. Morgan and Marshall also used the Lee and Emmons approach in the subsequent analysis of entrainment into the rising plume. This incorporated the use of an entrainment constant, $\alpha$, empirically determined by Lee and Emmons to have a value of 0.16. For a particular height of rise above the spill edge, this method then allows the mass flow rate of gases to be determined ignoring any entrainment of air into the ends of the plume. This method makes the fundamental assumption that the entrainment coefficient is constant, and profiles of velocity and temperature across the plume are Gaussian throughout. Morgan and Marshall also provide an expression to determine entrainment of air into the ends of the plume, which updated the method given in their original work [8]. The methods for calculating the EGS, the entrainment of air into the rising plume and into the ends of the plume are given in the user guide [1]. The total mass flow rate of gases of the spill plume, at a particular height of rise, is the sum of the entrainment into the plume and the entrainment into the ends. The BRE spill plume method should not be used for approach flow temperatures in excess of approximately $350{ }^{\circ} \mathrm{C}$. At present, in general, accurate calculation methods for high temperature flows do not exist.

\section{The effective layer depth correction}

One of the fundamental assumptions of the Lee and Emmons line plume theory is that the surrounding ambient air, through which the plume rises, remains at a uniform ambient temperature. Experimental studies $[8,14]$ have shown that this fundamental assumption can be violated depending upon the geometry of the smoke reservoir and the design smoke layer depth. A temperature gradient beneath the layer base can affect the subsequent entrainment of air into the plume [8,14].

To take this effect into account when using the BRE spill plume method, Morgan et al [1] describe the 'effective layer depth correction' to reduce the design the clear height of smoke layer above the spill edge. The reduced value is taken to be the design value minus $26 \%$ of the design layer depth. If the reduced clear height is less than $0.75 \mathrm{~m}$, then the correction should be ignored. 
Morgan et al [1] give classification criteria between 'large' and 'small' area smoke reservoirs to determine when this correction should be applied. The correction is required for 'large' area smoke reservoirs - namely when the design smoke layer depth is less than two-thirds of the characteristic width of the smoke reservoir (i.e. the square root of the cross-sectional area of the smoke reservoir).

Where the design smoke layer depth is greater than two-thirds of the characteristic width of the smoke reservoir, the reservoir can be classed as 'small' and no correction applies.

When using the BRE spill plume method, it is crucial that the designer identifies whether the effective layer depth correction applies to the particular design in question.

\section{SIMPLIFIED SPILL PLUME FORMULAE}

Simplified spill plume formulae typically consist of a single line equation to predict the mass flow rate of gases produced by a balcony spill plume. The majority of available simplified spill plume formulae are generally based on the assumption that the spill plume is generated from a virtual line source from below the spill edge. The depth of this virtual line source varies with respect to the fire size, the heat output per unit area of the fire and the compartment geometry. These simplified formulae are generally based on empirical approaches, and therefore have specific limitations depending on the way in which the correlation was derived. They have been derived from approach flows beneath a flat ceiling at the spill edge. Most of the available methods make the fundamental assumption of similarity between cross sectional distributions of velocity and temperature across the plume. These distributions are assumed to be Gaussian in nature throughout the full height of the plume. A summary of each of these simplified formulae and their limitations are described below.

\section{Methods by Law}

Law [3] developed a simplified spill plume formula by correlating the experimental data produced by Morgan and Marshall [7,8]. From this analysis, Law developed the following formula to determine the mass flow rate of gases produced by a balcony spill plume as given in Equation 4, where $h_{\text {comp }}$ is the height of the balcony above the base of the opening (and $Q_{T}$ is the total heat release rate).

$$
M_{p}=0.34\left(Q_{T} W^{2}\right)^{1 / 3}\left(z+0.15 h_{\text {comp }}\right)
$$

Equation 4 only applies to approach flows which are channelled by vertical screens and inherently includes entrainment of air into the free ends of the plume. Law [15] subsequently used a similar analysis using further experimental data from Hansell et al [14]. This analysis led to a revised correlation as given by Equation 5 .

$$
M_{p}=0.31\left(Q_{T} W^{2}\right)^{1 / 3}\left(z+0.25 h_{\text {comp }}\right)
$$


A modified version of Equation 5 is included within guidance given by the Chartered Institution of Building Service Engineers (CIBSE) in the UK [16] given by Equation 6 with the limit given by Equation 7 .

$$
\begin{aligned}
& M_{p}=0.36\left(Q W^{2}\right)^{1 / 3}\left(z+0.25 h_{\text {comp }}\right) \\
& \frac{Z}{W}<5
\end{aligned}
$$

\section{Method by Thomas}

Thomas [4] also used the experimental data from Morgan and Marshall [7,8] to develop a simplified balcony spill plume formula. Thomas also developed an explicit relationship to determine the entrainment of air into the free ends of the plume by modifying a previous analysis by Morgan and Marshall [7]. This relationship is included in Equation 8, to give the final form of a formula for balcony spill plumes.

$$
M_{p}=0.58 \rho\left(\frac{g Q_{T} W^{2}}{\rho c_{p, a i r} T_{1}}\right)^{1 / 3}\left(z+z_{0}\right)\left(1+\frac{0.22\left(z+2 z_{0}\right)}{W}\right)^{2 / 3}
$$

Using typical values for $g, \rho, c_{p, a i r}$, this equation reduces to:

$$
M_{p}=0.21 Q_{T}^{1 / 3}\left(z+z_{0}\right)\left(W+0.22\left(z+2 z_{0}\right)\right)^{2 / 3}
$$

One of the uncertainties in the above formula is the difficulty in selecting an appropriate location for the virtual line source, $z_{o}$. Thomas [4] provides a number of alternative locations of this virtual line source. Morgan et al [1] suggest that the location of the virtual source, as explicitly defined by Poreh et al [5], could be used in Equation 8 as a reasonable approximation.

\section{Method in NFPA 92B}

Current guidance on spill plume entrainment in the USA [17] uses a correlation which is described as being 'based on Law's interpretation of small-scale experiments by Morgan and Marshall' [see Equation 9]. This applies to balcony spill plumes only.

$$
M_{p}=0.41\left(Q W^{2}\right)^{1 / 3}\left(z+0.25 h_{\text {comp }}\right)
$$

With the limit that:

$$
\frac{z}{W}<13
$$




\section{Method by Poreh et al}

Using dimensional analysis, Poreh et al [5] deduced a relationship between the mass flow rate for a line plume and the convective heat flux of the gases. Poreh et al deduced the following simplified formula to determine the mass flow rate of gases due to a balcony spill plume [see Equation 11].

$$
\left(M_{p}-M_{b}\right)=B Q^{1 / 3} W^{2 / 3}\left(z+d_{b}\right)
$$

where,

$$
B=0.3 C_{m} \rho_{1}
$$

To determine the value of the constant $B$, Poreh et al used the data produced from five experimental studies of spill plumes described by Marshall and Harrison [18]. The correlated data determined the constant, $B=0.16$, for a balcony spill plume with no entrainment into the ends. This form of the Poreh et al method is given within guidance given in BS 7974 [19]. Poreh et al state that this calculation method only applies to balcony spill plumes and does not allow for entrainment of air into the free ends of the plume. It also applies to large area reservoirs from which the empirical constants were derived. This method should not be used for small area reservoirs.

\section{Method by Thomas et al}

Thomas et al [6] used a rigorous dimensional analysis in the development of a simplified spill plume model. This method does not require an explicit term to specify the location of the virtual line source, nor does it make the assumption of self-similar flow profiles in terms of temperature and velocity throughout the plume. Thomas et al used the data given by Marshall and Harrison [18] and Poreh et al [5] in the development of the calculation method. This method requires the prior calculation of the mass flow rate and convective heat flux of the gases at the spill edge. Thomas et al provided the following simplified spill plume formula [Equation 12], which applies to balcony spill plumes with no end entrainment in large area smoke reservoirs.

$$
M_{p}=0.16 z Q^{1 / 3} W^{2 / 3}+0.0027 Q+1.2 M_{b}
$$

Thomas et al also provided an alternative version of the spill plume formula provided by Poreh et al [5], so that it was in the same form as Equation 12. This form of the Thomas et al method (Equation 13) is given within guidance on spill plumes given in BS 7974 [19]. This formula applies to balcony spill plumes without entrainment of air into the ends.

$$
M_{p}=0.16 z Q^{1 / 3} W^{2 / 3}+0.0014 Q+1.4 M_{b}
$$

Thomas et al also analysed statistically the data of Hansell et al [14], where the plume ends were free. They obtained: 


$$
\begin{aligned}
& \frac{M_{p}^{\prime}}{Q^{\prime}}=0.342 \frac{Z}{\left(Q^{\prime}\right)^{2 / 3}}+2.64 \frac{M_{b}^{\prime}}{Q^{\prime}}-0.0083 \\
& M_{p}^{\prime}=\frac{M_{p}}{W} ; \quad Q^{\prime}=\frac{Q}{W}
\end{aligned}
$$

With the limit that:

$$
\frac{Z}{W}<3
$$

\section{PHYSICAL SCALE MODELLING}

The technical approach for this study was physical scale modelling. This approach is well established and has been used in many studies of smoke movement in buildings. The approach described in this report was primarily developed at the Fire Research Station in the UK $[20,21]$ and typically takes the form of reduced scale fires within a physical model. The approach is also described by Quintiere [22] and Klote and Milke [23], and it is included in NFPA 92B [17]. Measurements are generally made of temperature, velocity and gas concentrations, in addition to visual observations. Measurements can be extrapolated to full scale using the appropriate scaling laws. To ensure that the results can be extrapolated to full scale, the physical scale model used in this study was designed to meet the scaling principles set out by Thomas et al [20]. This is effectively a modified Froude number scaling and requires that the equivalent flows are fully turbulent on both full and model scale. Dimensional relationships between fluid dynamic variables, which can be derived from first principles, are described elsewhere [24]. These relationships can be simplified by holding one of these variables constant to derive the scaling laws. For experimental modelling, it is convenient to keep the temperature above ambient equal on both full and model scale. Hence, the same temperature must apply to the corresponding points in the flow system, irrespective of scale. The scaling laws can then be described by,

$$
\begin{aligned}
& Q \propto L^{5 / 2} \\
& M \propto L^{5 / 2} \\
& V \propto L^{5 / 2} \\
& u \propto L^{1 / 2}
\end{aligned}
$$

and the time scale $\tau$, which is described for the flow system by,

$$
\tau \propto \frac{L}{u} \propto L^{1 / 2}
$$


It should be noted that all of the above applies only to a flow that is fully turbulent, is driven by buoyancy forces alone and where there are large variations in density of the hot gases. It should be noted that the above scaling laws do not describe either conductive or radiative heat transfer processes. If either is present to a significant extent in the flow system, the scaling laws given here cannot be applied. The modelling technique used for this application was designed to minimise both of these, but a method of partial scaling of conductive heat transfer is described by Quintiere [22] and Klote and Milke [23].

\section{THE EXPERIMENT}

\section{The physical scale model}

The apparatus used for this work was a $1 / 10^{\text {th }}$ physical scale model (see Figure 2). The model essentially consisted of a steel frame with ceramic fibre insulation (CFI) boards attached. The ceramic boards were protected on the external surfaces by a $2 \mathrm{~mm}$ thick steel substrate. The model simulated a fire within a communicating space in an atrium building, and consisted of two main units, the fire compartment and the smoke exhaust hood.

The fire compartment was constructed from $20 \mathrm{~mm}$ thick CFI board with a $2 \mathrm{~mm}$ thick steel substrate on each external face. As the lateral extent of the spill plume tended to broaden as the height of rise increased (with end entrainment), preliminary tests were carried out to determine an appropriate width of fire compartment opening so that the plume would be contained within the $1.0 \mathrm{~m}$ wide smoke exhaust hood. An appropriate width of compartment opening was determined to be $0.6 \mathrm{~m}$ to contain smoke within the hood for all of the tests. The opening was $0.5 \mathrm{~m}$ high, which was the full height of the fire compartment. A $0.3 \mathrm{~m}$ broad balcony constructed from $10 \mathrm{~mm}$ thick CFI board with a $2 \mathrm{~mm}$ thick steel substrate on its upper face, was attached to the fire compartment opening and extended across its full width. Channelling screens made from $10 \mathrm{~mm}$ thick CFI board were located at each side of the compartment opening beneath the balcony and occupied the full breadth of the balcony. The channelling screens were used to provide reasonably homogeneous temperature and velocity profiles across the width of the opening. This enabled the mass flow rate of gases at the spill edge to be determined from a single velocity and temperature traverse through the smoke layer. The channelling screens extended to the floor as in previous work $[14,18]$. In reality, these channelling screens would not occupy the full height of the compartment, but would be deep enough to contain the approach flow beneath the balcony. However, in the experiment, the channelling screens were made full height to contain all possible approach flows for the range of conditions studied. The flow conditions at the compartment opening are likely to be similar, either when using full height or short channelling screens, provided that the approach flow is contained within the screens. The balcony was modified such that a downstand could be attached at the spill edge. There were 2 downstands used, $0.1 \mathrm{~m}$ and $0.2 \mathrm{~m}$ deep. Each downstand was made from $10 \mathrm{~mm}$ thick CFI board.

The side walls of the smoke exhaust hood were generally constructed from $10 \mathrm{~mm}$ thick CFI board with a $2 \mathrm{~mm}$ thick steel sheet substrate on each external face. However, one of the (long length) side walls was constructed from $12 \mathrm{~mm}$ thick 
transparent acrylic sheet to enable visual observations to be made of the smoke layer within the collecting hood. The model was designed such that the walls could freely move in a vertical direction within the supporting frame. This enabled each wall to be moved independently to the base of the observed smoke layer in the hood. This prevented warming of the air beneath the observed smoke layer through which the plume rises. The supporting steel frame was designed such that each side wall could contain up to two, smaller, modular walls which could be bolted together. This would then form a single wall on each face when examining deep smoke layers within the collecting hood. The short length side walls consisted of modular panels each $1.0 \mathrm{~m}$ wide by $1.2 \mathrm{~m}$ high, the long length panels each were $2.0 \mathrm{~m}$ wide by $1.2 \mathrm{~m}$ high.

The mechanical smoke exhaust system from the hood consisted of a $440 \mathrm{~mm}$ diameter bifurcated fan attached to the hood outlet using high temperature flexible ducting. The gases were exhausted to the outside of the laboratory through flexible ducting which was connected to the exhaust end of the fan. The fan speed was controllable, which enabled different exhaust rates, and hence, variation in the height of rise of the plume to be examined.

The fire source was generated by supplying Industrial Methylated Spirits (IMS) into a metal tray within the fire compartment at a controlled and measured rate. The metal tray was located at the rear of the fire compartment. Since the fuel did not occupy the full area of the tray, the tray was tilted toward the back of the compartment at an angle of $45^{\circ}$ to the walls of the compartment. Hence, the sides of the fire tray channelled the fuel such that its surface remained reasonably uniform and automatically adjusted to match the burning rate to the inflow of fuel. The tray was $0.25 \mathrm{~m}$ by $0.25 \mathrm{~m}$ by 0.015 $\mathrm{m}$ high. The hot gases produced from the fire were visualised by injecting smoke from a commercial smoke generator into the fire compartment. This highlighted the flowing gas layer from the compartment and the subsequent spill plume and smoke layer in the collecting hood. 

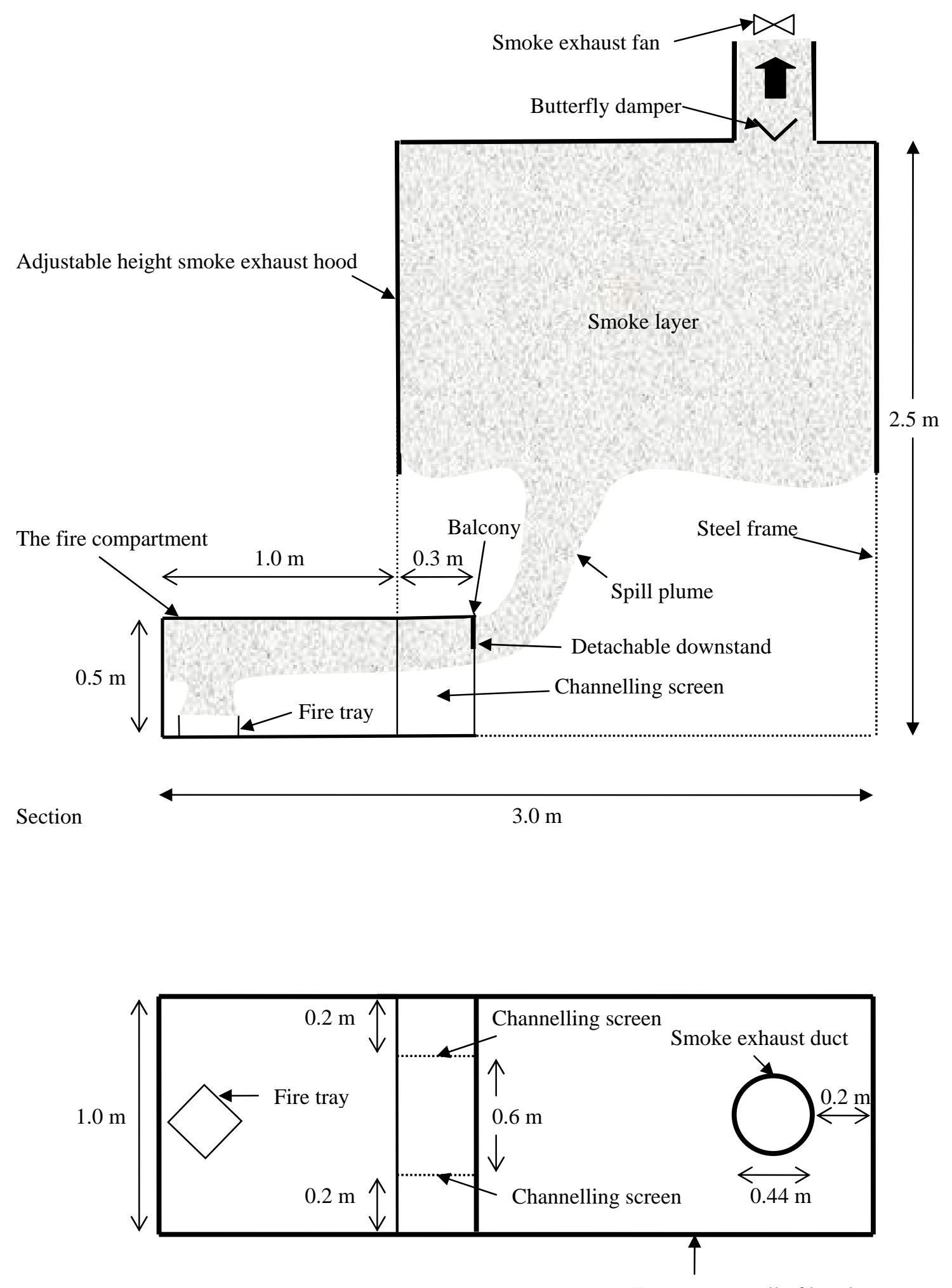

Plan

Transparent wall of hood

Figure 2: Schematic drawing of the $1 / 10^{\text {th }}$ physical scale model 


\section{Instrumentation and measurements}

The gas temperatures in the model were measured using $0.5 \mathrm{~mm}$ diameter bare wire chromel/alumel (K-type) thermocouples. Thermocouples were positioned at various locations in the model (see Figure 3), as follows:

- 1 column of 24 thermocouples (Column A) located within the smoke exhaust hood

- 1 column of 18 thermocouples (Column B) located centrally beneath the spill edge (under the balcony)

- An array of 5 thermocouples (Array A) spaced equally across the width of the spill edge, projecting $10 \mathrm{~mm}$ below the edge

- 1 thermocouple located centrally within the smoke exhaust duct $5.0 \mathrm{~m}$ downstream of the exhaust vent

- 1 thermocouple located next to a pitot-static tube when carrying out velocity traverses of the smoke layer at the spill edge.

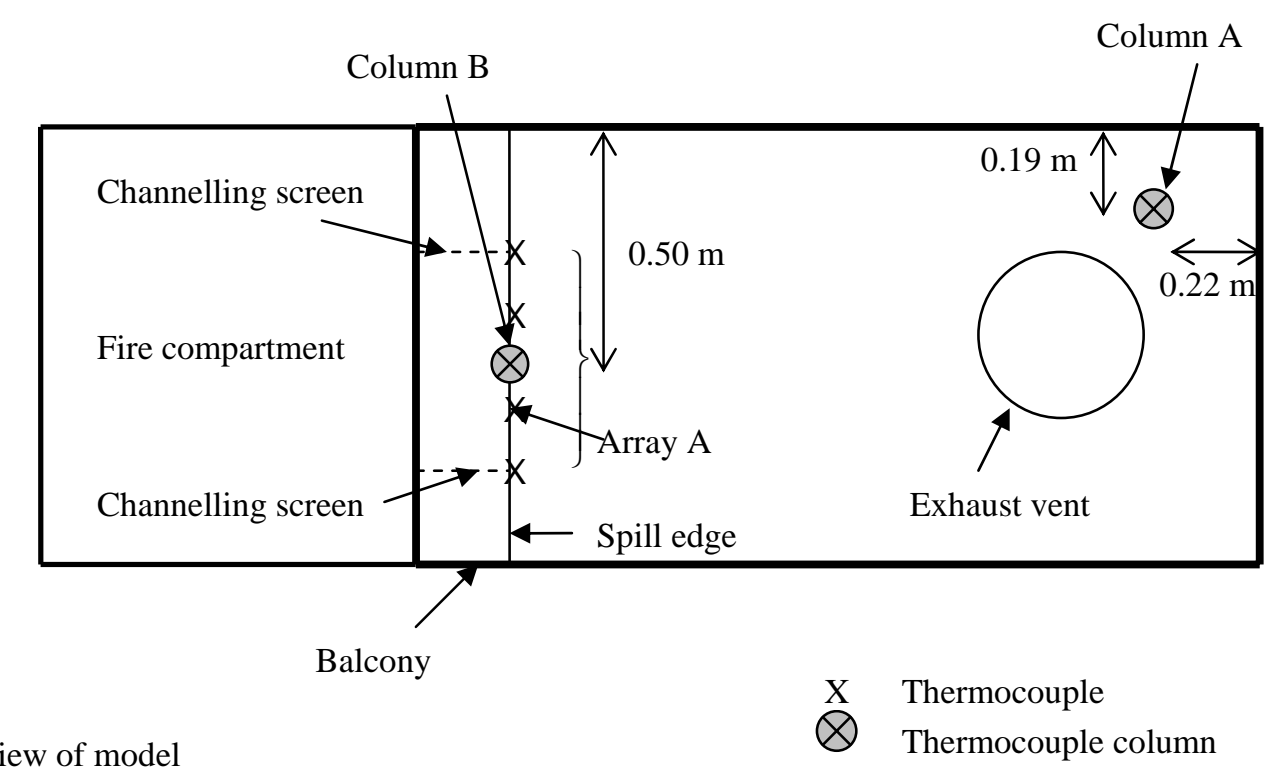

Plan view of model

Thermocouple column

Figure 3: Thermocouple locations

A perforated gas sampling tube was located in the exhaust duct approximately $5.0 \mathrm{~m}$ downstream of the vent in the smoke exhaust hood. This enabled measurement of the $\mathrm{CO}_{2}$ gas concentration in the duct to be made using an infra red gas analyser. The mass flow rate of gases entering the buoyant gas layer in the smoke exhaust hood and therefore leaving the hood, was found by using a $\mathrm{CO}_{2}$ tracer gas technique and calculation method [21].

Vertical velocity and temperature profiles of the buoyant gas layer flow at the spill edge were made using a pitot-static tube and a thermocouple. The pitot-static tube was located in a central position beneath the balcony at the spill edge, and connected to a sensitive capacitive differential pressure transducer (+/- $5 \mathrm{~Pa}$ full scale range, accuracy $+/-0.25 \%$ of reading). Gas velocity measurements were made every $10 \mathrm{~mm}$ 
below the spill edge until the base of the smoke layer was reached. This measurement, in addition to the temperature profiles, enabled the mass flow rate and convective heat flux of the layer flow at the spill edge to be determined. The total mass flow rate of gases at the spill edge was then determined by performing an integration under the curve of $W \rho u$ with respect to the depth of the gas layer. Similarly, the convective heat flux of the gases at the spill edge was determined using the results of the vertical velocity and temperature profiles. The convective heat flux was determined by performing an integration under the curve of $W \rho u c_{p} \theta$ with respect to the depth of the gas layer.

\section{Parameter variation}

Table 1 shows a summary of the parameter variation for the series of test fires. For the vast majority of tests, a balcony spill plume was examined allowing air entrainment into the free ends. The lateral extent of the plume at the spill edge was fixed at $0.6 \mathrm{~m}$ with the use of channelling screens at the compartment opening. The cross sectional area of the smoke exhaust hood also remained fixed ( $2.0 \mathrm{~m}$ long by $1.0 \mathrm{~m}$ wide). The total heat output of the fire was varied. Three fire sizes were examined with a total heat output of 6,9 and $12 \mathrm{~kW}$ respectively. This equates to a fire size of 1.9, 2.8 and 3.8 MW respectively for a full scale equivalent using the scaling laws. A maximum fire size of $12 \mathrm{~kW}$ was chosen so that the temperature at the spill edge did not exceed $300^{\circ} \mathrm{C}$ for any of the test fires thus, not exceeding the maximum spill edge temperature at which the current theories can be applied. Varying the total heat output in turn varied the mass flow rate and convective heat flux of the gases at the spill edge, in addition to varying the depth of the resulting smoke layer. The effect of a downstand at the spill edge was examined. Two downstand depths were used, $0.1 \mathrm{~m}$ and $0.2 \mathrm{~m}$ deep respectively. The effect of no downstand at the spill edge (i.e. a flat ceiling) was also examined. The height of rise of the plume was also varied. A single test (Test 43) was also carried out without entrainment of air into the ends of the plume for a $1.0 \mathrm{~m}$ wide opening. This was done as a check to confirm that the results from the model were consistent with earlier work [5]. 
Table 1: Parameter variation for the series of test fires

\begin{tabular}{ccccc}
\hline Test & $\begin{array}{c}\text { downstand } \\
\text { depth }\end{array}$ & $\mathbf{z}_{\mathbf{d}}$ & $\mathbf{z}$ & $\mathbf{Q}_{\mathbf{T}}$ \\
& $\mathbf{( m )}$ & $\mathbf{( m )}$ & $\mathbf{( m )}$ & $\mathbf{( k W )}$ \\
\hline 1 & 0.2 & 1.1 & 0.9 & 6.0 \\
2 & 0.2 & 1.1 & 0.9 & 9.0 \\
3 & 0.2 & 1.1 & 0.9 & 12.0 \\
4 & 0.0 & 0.6 & 0.6 & 6.0 \\
5 & 0.0 & 0.6 & 0.6 & 9.0 \\
6 & 0.0 & 0.6 & 0.6 & 12.0 \\
7 & 0.1 & 0.7 & 0.6 & 6.0 \\
8 & 0.1 & 0.7 & 0.6 & 9.0 \\
9 & 0.1 & 0.7 & 0.6 & 12.0 \\
10 & 0.2 & 0.8 & 0.6 & 6.0 \\
11 & 0.2 & 0.8 & 0.6 & 9.0 \\
12 & 0.2 & 0.8 & 0.6 & 12.0 \\
13 & 0.0 & 0.5 & 0.5 & 6.0 \\
14 & 0.0 & 0.5 & 0.5 & 9.0 \\
15 & 0.0 & 0.5 & 0.5 & 12.0 \\
16 & 0.2 & 0.7 & 0.5 & 6.0 \\
17 & 0.2 & 0.7 & 0.5 & 9.0 \\
18 & 0.2 & 0.7 & 0.5 & 12.0 \\
19 & 0.1 & 0.5 & 0.4 & 6.0 \\
20 & 0.1 & 0.5 & 0.4 & 9.0 \\
21 & 0.1 & 0.5 & 0.4 & 12.0 \\
22 & 0.0 & 0.3 & 0.3 & 6.0 \\
23 & 0.0 & 0.3 & 0.3 & 9.0 \\
24 & 0.0 & 0.3 & 0.3 & 12.0 \\
25 & 0.2 & 0.5 & 0.3 & 6.0 \\
26 & 0.2 & 0.5 & 0.3 & 9.0 \\
27 & 0.2 & 0.5 & 0.3 & 12.0 \\
28 & 0.1 & 0.3 & 0.2 & 6.0 \\
29 & 0.1 & 0.3 & 0.2 & 9.0 \\
30 & 0.1 & 0.3 & 0.2 & 12.0 \\
31 & 0.2 & 0.3 & 0.1 & 6.0 \\
32 & 0.2 & 0.3 & 0.1 & 9.0 \\
33 & 0.2 & 0.3 & 0.1 & 12.0 \\
34 & 0.0 & 0.0 & 0.0 & 6.0 \\
35 & 0.0 & 0.0 & 0.0 & 9.0 \\
36 & 0.0 & 0.0 & 0.0 & 12.0 \\
37 & 0.1 & 0.0 & -0.1 & 6.0 \\
38 & 0.1 & 0.0 & -0.1 & 9.0 \\
39 & 0.1 & 0.0 & -0.1 & 12.0 \\
40 & 0.2 & 0.0 & -0.2 & 6.0 \\
41 & 0.2 & 0.0 & -0.2 & 9.0 \\
42 & 0.2 & 0.0 & -0.2 & 12.0 \\
43 & 0.0 & 0.3 & 0.3 & 6.0 \\
\hline & & & & \\
& 0.0
\end{tabular}

Test 43 was without entrainment of air into the ends for a $1.0 \mathrm{~m}$ wide opening 


\section{RESULTS AND DISCUSSION}

\section{Plume behaviour - flat ceiling at the spill edge}

The smoke layer within the fire compartment was observed to flow out from the opening, rotate at the spill edge, and rise as a spill plume which was approximately two-dimensional in nature. Figure 4 shows a photograph of the typical spill plume behaviour as it emerged from the fire compartment opening. Figure 4 shows that the resulting plume horizontally projected beyond the compartment opening before rising as a plume. This projection was due to the momentum of the horizontal approach flow with the compartment. Visual observations identified entrainment of air occurring across the lateral extent of the spill plume by the generation of vortices being shed from the outer edges.

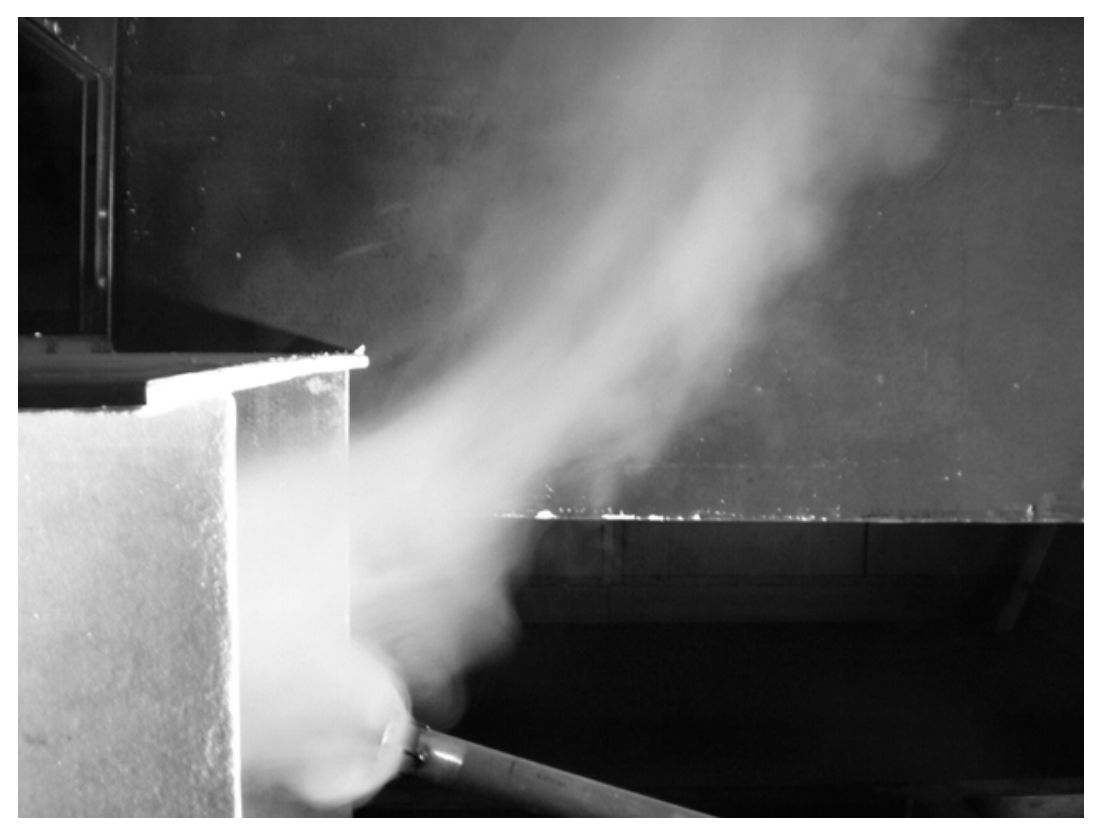

Figure 4: Spill plume behaviour from a compartment with a flat ceiling

These vortices are generally known as "vortex rolls". Larger vortices were observed on the front edge of the spill plume (furthest from the spill edge). Entrainment of air was also observed into the free ends of the plume as it entered into the smoke exhaust hood. The ends of the plume behaved in a "spiral" motion as the plume rose. The lateral extent of the plume was observed to broaden as the height of rise increased. However, the plume was contained within the smoke exhaust hood for all the tests carried out. 


\section{Plume behaviour - $0.1 \mathrm{~m}$ downstand at the spill edge}

A similar plume behaviour was observed when a $0.1 \mathrm{~m}$ downstand was present at the spill edge. However, the presence of the downstand acted as a baffle, which caused the momentum of the horizontal flow from the opening to be reduced compared to the scenario with a flat ceiling. The spill plume was observed to be more vertical in nature (see Figure 5), possessing less horizontal projection when emerging from the opening. The general entrainment processes across the lateral extent and into the free ends of the spill plume were similar to that described above. The presence of the downstand limited the amount of entrainment into the back edge of the plume over the depth of the downstand, with the plume effectively being adhered in this region.

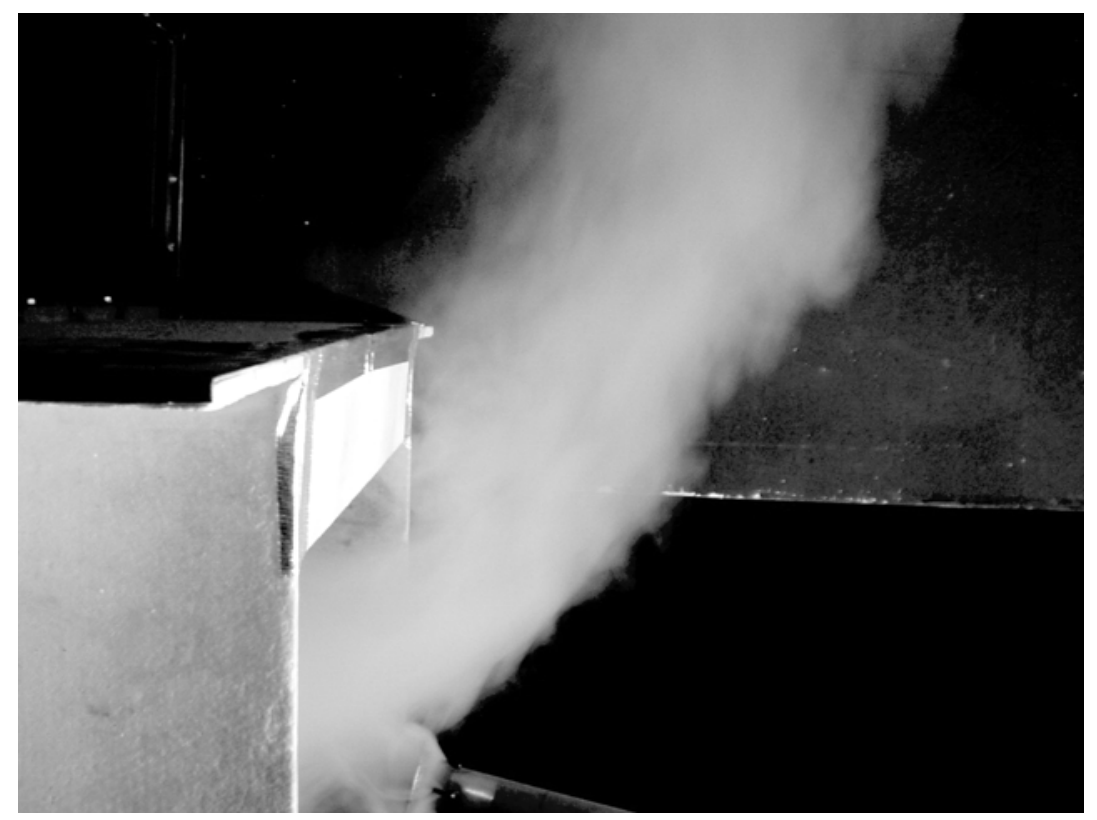

Figure 5: Spill plume behaviour from a compartment with a $0.1 \mathrm{~m}$ downstand

\section{Plume behaviour $-0.2 \mathrm{~m}$ downstand at the spill edge}

Figure 6 shows a photograph of the emerging spill plume when a $0.2 \mathrm{~m}$ downstand was present at the spill edge. Figure 6 shows that the spill plume rises vertically when emerging from the compartment opening. This behaviour is again likely to be due to the deep downstand acting as a baffle, which significantly reduced the momentum of the approach flow from the opening. The emerging plume has little horizontal projection and rises vertically from the spill edge. The rising plume was also observed to migrate toward the rear wall of the exhaust hood for those tests with a high height of rise. This behaviour has significant implications for smoke logging on higher balconies, due to partial impingement of the rising plume with the balconies above. Entrainment of air was also observed to occur across the lateral extent of the spill plume, again via the generation of vortices on either edge of the plume. These vortices were observed to be similar in nature and size on both edges of the spill plume. Entrainment of air also occurred into the free ends of the plume with a similar behaviour to that described above. The presence of the deep downstand effectively caused the plume to be adhered over the entire downstand depth, with little entrainment into the rear edge of the plume in this region. 


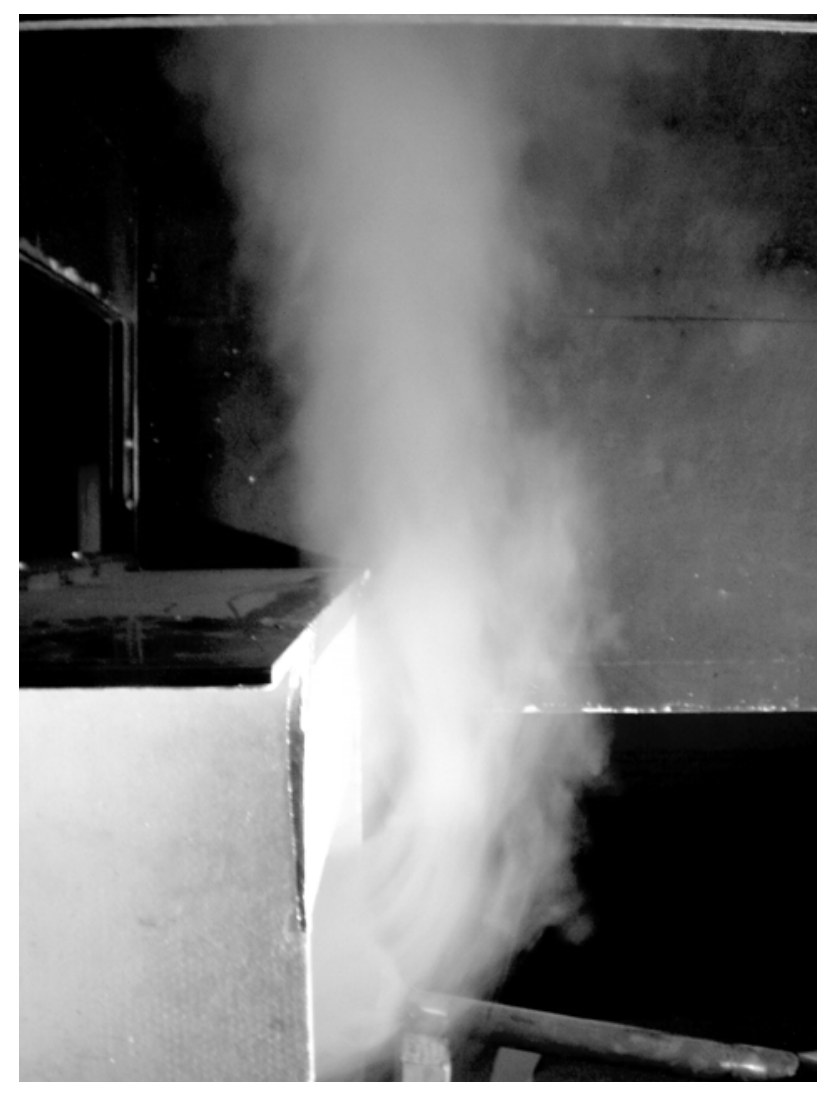

Figure 6: Spill plume behaviour from a compartment with a $0.2 \mathrm{~m}$ downstand

\section{Smoke layer in exhaust hood}

In general, the rising spill plume subsequently gave rise to a layer with a reasonably uniform depth within the smoke exhaust hood. Figure 2 shows a schematic drawing of the typical smoke layer behaviour observed. Fresh air was allowed to be entrained into the rising plume directly beneath the smoke layer, such that there was no warming of the air beneath the layer. Figure 7 shows a photograph of a layer in the smoke exhaust hood for a plume with a flat ceiling at the spill edge. It should be noted that the rear wall (long length) of the hood had been lowered for photographic purposes only. In the experiment, the walls of the hood were at an identical height above the spill edge. 


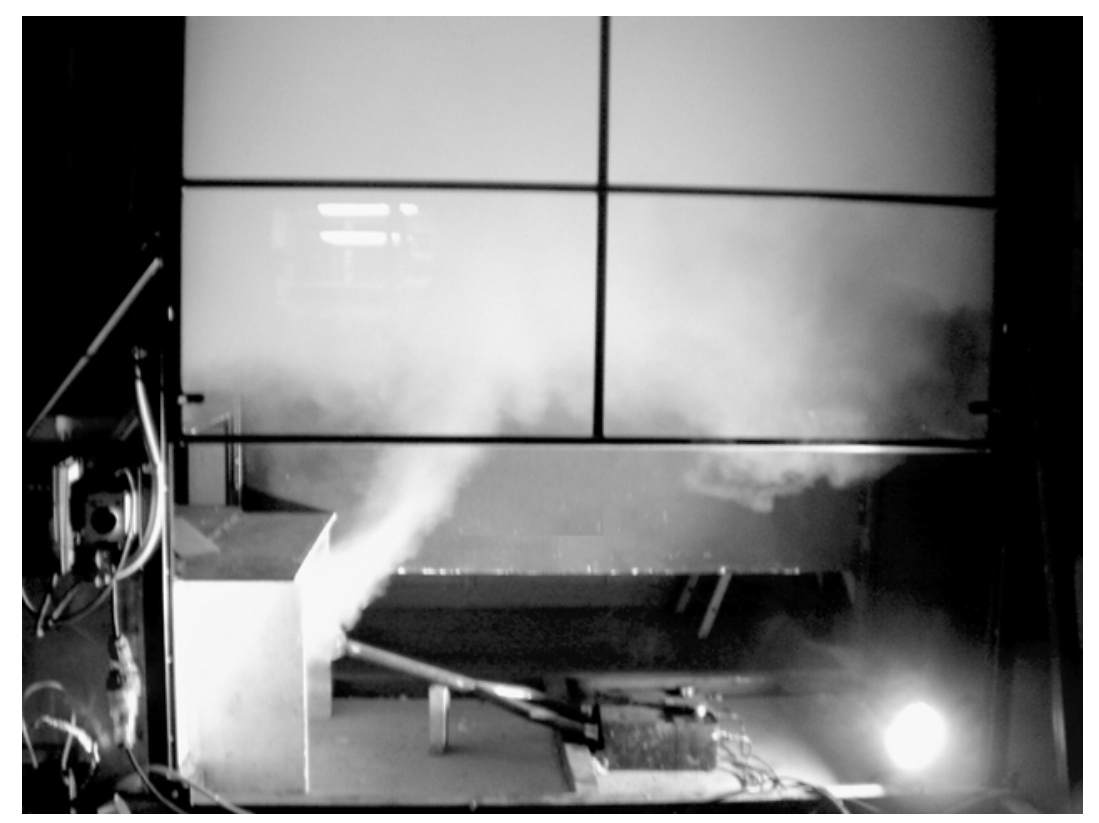

Figure 7: The smoke layer in the exhaust hood

\section{Error analysis}

Although the experimental measurements were made during relatively steady state conditions, fluctuations in various measurements (e.g. temperature, velocity, mass flow rate) occurred during the sampling period. Therefore, the experimental results were determined in terms of a time averaged mean value with an associated standard error. The standard error was determined by dividing the standard deviation of the sample by the square root of the number of samples. Table 2 shows a summary of the experimental results and the associated standard errors for the series of test fires. 
Table 2: Summary of results

\begin{tabular}{|c|c|c|c|c|c|}
\hline Test & $\begin{array}{c}\mathbf{Q} \\
(\mathrm{kW})\end{array}$ & $\begin{array}{l}d_{b} \\
(m)\end{array}$ & $\begin{array}{l}\theta_{b, \max } \\
\left({ }^{\circ} \mathrm{C}\right)\end{array}$ & $\begin{array}{c}\mathrm{M}_{\mathrm{b}} \\
\left(\mathrm{kgs}^{-1}\right)\end{array}$ & $\begin{array}{c}M_{p} \\
\left(k^{-1}\right)\end{array}$ \\
\hline 1 & $4.11+/-0.59$ & $0.105+/-0.010$ & $161.70+/-3.15$ & $0.0332+/-0.0058$ & $0.3225+/-0.0094$ \\
\hline 2 & $6.34+/-1.36$ & $0.110+/-0.010$ & $210.20+/-6.58$ & $0.0388+/-0.0130$ & $0.3433+/-0.0068$ \\
\hline 3 & $8.74+/-1.38$ & $0.115+/-0.010$ & $258.60+/-5.97$ & $0.0408+/-0.0076$ & $0.3800+/-0.0056$ \\
\hline 4 & $4.89+/-0.53$ & $0.130+/-0.010$ & $104.20+/-2.91$ & $0.0584+/-0.0073$ & $0.2542+/-0.0074$ \\
\hline 5 & $7.40+/-0.78$ & $0.140+/-0.010$ & $132.60+/-5.13$ & $0.0682+/-0.0083$ & $0.2798+/-0.0055$ \\
\hline 6 & $10.37+/-1.25$ & $0.150+/-0.010$ & $166.60+/-7.03$ & $0.0749+/-0.0108$ & $0.2975+/-0.0043$ \\
\hline 7 & $4.33+/-0.46$ & $0.125+/-0.010$ & $121.80+/-2.02$ & $0.0428+/-0.0049$ & $0.2320+/-0.0067$ \\
\hline 8 & $6.33+/-0.77$ & $0.130+/-0.010$ & $158.50+/-4.32$ & $0.0483+/-0.0064$ & $0.2856+/-0.0057$ \\
\hline 9 & $9.10+/-1.03$ & $0.140+/-0.010$ & $200.60+/-2.15$ & $0.0543+/-0.0067$ & $0.2971+/-0.0043$ \\
\hline 10 & $4.11+/-0.59$ & $0.105+/-0.010$ & $161.70+/-3.15$ & $0.0332+/-0.0058$ & $0.2520+/-0.0073$ \\
\hline 11 & $6.34+/-1.36$ & $0.110+/-0.010$ & $210.20+/-6.58$ & $0.0388+/-0.0130$ & $0.2750+/-0.0055$ \\
\hline 12 & $8.74+/-1.38$ & $0.115+/-0.010$ & $258.60+/-5.97$ & $0.0408+/-0.0076$ & $0.2896+/-0.0042$ \\
\hline 13 & $4.89+/-0.53$ & $0.130+/-0.010$ & $104.20+/-2.91$ & $0.0584+/-0.0073$ & $0.2135+/-0.0062$ \\
\hline 14 & $7.40+/-0.78$ & $0.140+/-0.010$ & $132.60+/-5.13$ & $0.0682+/-0.0083$ & $0.2429+/-0.0048$ \\
\hline 15 & $10.37+/-1.25$ & $0.150+/-0.010$ & $166.60+/-7.03$ & $0.0749+/-0.0108$ & $0.2600+/-0.0037$ \\
\hline 16 & $4.11+/-0.59$ & $0.105+/-0.010$ & $161.70+/-3.15$ & $0.0332+/-0.0058$ & $0.2083+/-0.0060$ \\
\hline 17 & $6.34+/-1.36$ & $0.110+/-0.010$ & $210.20+/-6.58$ & $0.0388+/-0.0130$ & $0.2351+/-0.0047$ \\
\hline 18 & $8.74+/-1.38$ & $0.115+/-0.010$ & $258.60+/-5.97$ & $0.0408+/-0.0076$ & $0.2648+/-0.0038$ \\
\hline 19 & $4.33+/-0.46$ & $0.125+/-0.010$ & $121.80+/-2.02$ & $0.0428+/-0.0049$ & $0.2038+/-0.0059$ \\
\hline 20 & $6.33+/-0.77$ & $0.130+/-0.010$ & $158.50+/-4.32$ & $0.0483+/-0.0064$ & $0.2342+/-0.0046$ \\
\hline 21 & $9.10+/-1.03$ & $0.140+/-0.010$ & $200.60+/-2.15$ & $0.0543+/-0.0067$ & $0.2463+/-0.0035$ \\
\hline 22 & $4.89+/-0.53$ & $0.130+/-0.010$ & $104.20+/-2.91$ & $0.0584+/-0.0073$ & $0.1777+/-0.0052$ \\
\hline 23 & $7.40+/-0.78$ & $0.140+/-0.010$ & $132.60+/-5.13$ & $0.0682+/-0.0083$ & $0.1932+/-0.0038$ \\
\hline 24 & $10.37+/-1.25$ & $0.150+/-0.010$ & $166.60+/-7.03$ & $0.0749+/-0.0108$ & $0.2108+/-0.0030$ \\
\hline 25 & $4.11+/-0.59$ & $0.105+/-0.010$ & $161.70+/-3.15$ & $0.0332+/-0.0058$ & $0.1550+/-0.0045$ \\
\hline 26 & $6.34+/-1.36$ & $0.110+/-0.010$ & $210.20+/-6.58$ & $0.0388+/-0.0130$ & $0.1792+/-0.0036$ \\
\hline 27 & $8.74+/-1.38$ & $0.115+/-0.010$ & $258.60+/-5.97$ & $0.0408+/-0.0076$ & $0.1931+/-0.0028$ \\
\hline 28 & $4.33+/-0.46$ & $0.125+/-0.010$ & $121.80+/-2.02$ & $0.0428+/-0.0049$ & $0.1269+/-0.0037$ \\
\hline 29 & $6.33+/-0.77$ & $0.130+/-0.010$ & $158.50+/-4.32$ & $0.0483+/-0.0064$ & $0.1483+/-0.0029$ \\
\hline 30 & $9.10+/-1.03$ & $0.140+/-0.010$ & $200.60+/-2.15$ & $0.0543+/-0.0067$ & $0.1758+/-0.0025$ \\
\hline 31 & $4.11+/-0.59$ & $0.105+/-0.010$ & $161.70+/-3.15$ & $0.0332+/-0.0058$ & $0.1090+/-0.0033$ \\
\hline 32 & $6.34+/-1.36$ & $0.110+/-0.010$ & $210.20+/-6.58$ & $0.0388+/-0.0130$ & $0.1335+/-0.0026$ \\
\hline 33 & $8.74+/-1.38$ & $0.115+/-0.010$ & $258.60+/-5.97$ & $0.0408+/-0.0076$ & $0.1571+/-0.0023$ \\
\hline 34 & $4.89+/-0.53$ & $0.130+/-0.010$ & $104.20+/-2.91$ & $0.0584+/-0.0073$ & $0.0886+/-0.0024$ \\
\hline 35 & $7.40+/-0.78$ & $0.140+/-0.010$ & $132.60+/-5.13$ & $0.0682+/-0.0083$ & $0.0926+/-0.0018$ \\
\hline 36 & $10.37+/-1.25$ & $0.150+/-0.010$ & $166.60+/-7.03$ & $0.0749+/-0.0108$ & $0.1090+/-0.0016$ \\
\hline 37 & $4.33+/-0.46$ & $0.125+/-0.010$ & $121.80+/-2.02$ & $0.0428+/-0.0049$ & $0.0716+/-0.0021$ \\
\hline 38 & $6.33+/-0.77$ & $0.130+/-0.010$ & $158.50+/-4.32$ & $0.0483+/-0.0064$ & $0.0814+/-0.0016$ \\
\hline 39 & $9.10+/-1.03$ & $0.140+/-0.010$ & $200.60+/-2.15$ & $0.0543+/-0.0067$ & $0.0886+/-0.0013$ \\
\hline 40 & $4.11+/-0.59$ & $0.105+/-0.010$ & $161.70+/-3.15$ & $0.0332+/-0.0058$ & $0.0570+/-0.0017$ \\
\hline 41 & $6.34+/-1.36$ & $0.110+/-0.010$ & $210.20+/-6.58$ & $0.0388+/-0.0130$ & $0.0645+/-0.0013$ \\
\hline 42 & $8.74+/-1.38$ & $0.115+/-0.010$ & $258.60+/-5.97$ & $0.0408+/-0.0076$ & $0.0708+/-0.0010$ \\
\hline 43 & $4.62+/-0.50$ & $0.110+/-0.010$ & $89.10+/-1.60$ & $0.0710+/-0.1000$ & $0.1855+/-0.0054$ \\
\hline
\end{tabular}




\section{Mass flow rate of gases with entrainment of air into the ends - the 3-D plume}

In an attempt to develop a simplified spill plume formula to predict the mass flow rate of gases due to a balcony spill plume, including the entrainment of air into the ends, the experimental results were initially correlated using the method by Poreh et al [5]. The flat ceiling data were correlated in the form described by Equation 11 to empirically determine a value of the constant, $B$. This equation correlates the mass of air entrained in the vertically rising plume $\left(M_{p}-M_{b}\right)$ with $Q^{1 / 3} W^{2 / 3}\left(z+d_{b}\right)$. The data for each downstand were correlated in the same way but used $\left(z_{d}+d_{b}\right)$ instead of $\left(z+d_{b}\right)$, where $z_{d}$ denotes the height of rise of the plume above the spill edge of the downstand (i.e. $z$ plus the depth of the downstand). The three correlations were similar as demonstrated in Figure 8, which shows all the experimental data.

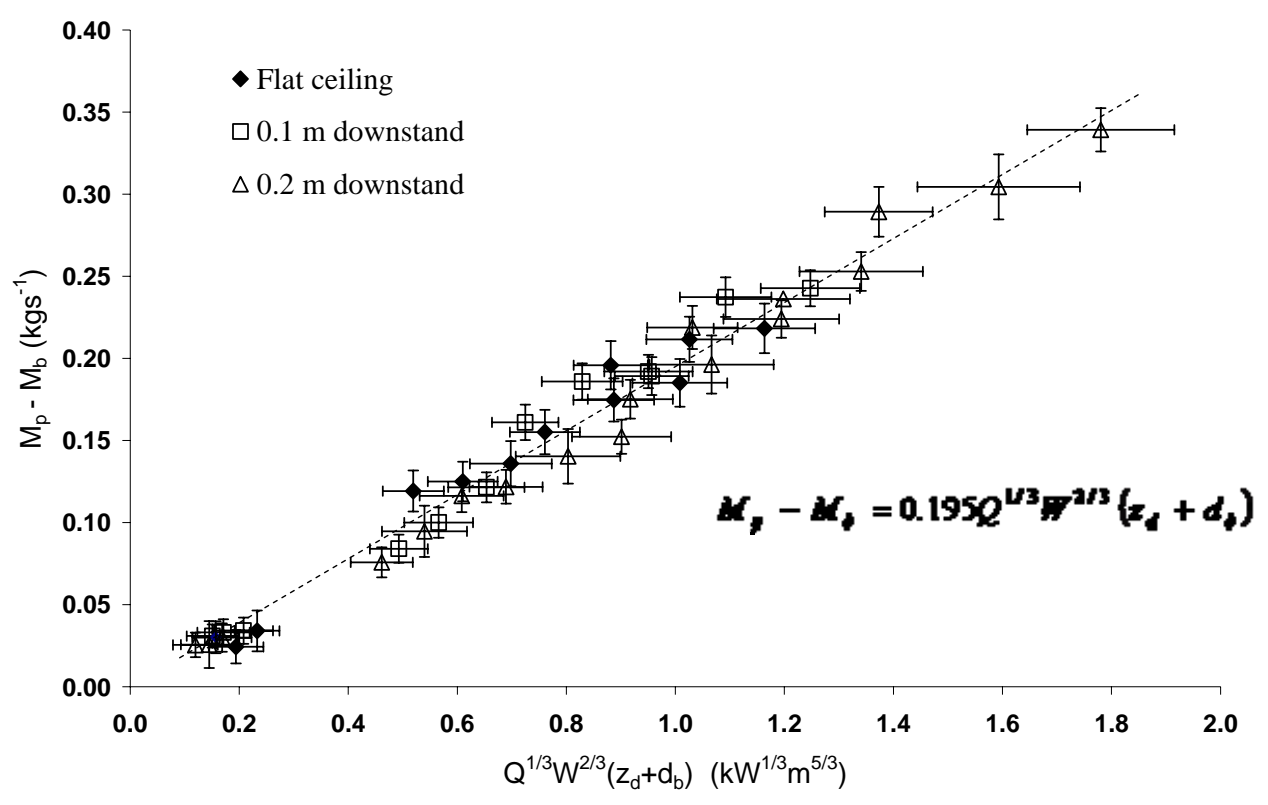

Figure 8: $\left(M_{p}-M_{b}\right)$ with respect to $Q^{1 / 3} W^{2 / 3}\left(z_{d}+d_{b}\right)$ for all the experimental data

The entrainment of air into the spill plume appears to be the same, whether the spill edge is at the downstand edge or at the balcony edge. Accordingly, the results were correlated as a single data series according to the method by Poreh et al [5] to determine the value of the constant, $B$. Figure 8 shows that the variation in $\left(M_{p}-M_{b}\right)$ with respect to $Q^{1 / 3} W^{2 / 3}\left(z_{d}+d_{b}\right)$ can generally be described by a linear relationship.

Figure 8 shows the line of best fit through the data set. This line of best fit is described by Equation 18.

$$
M_{p}-M_{b}=0.195 Q^{1 / 3} W^{2 / 3}\left(z_{d}+d_{b}\right)
$$

Note that $z_{d}=z$ for no downstand. 
Hence the constant, $B$, given in Equation 18 is equal to 0.195 in this case. It is therefore proposed, that for design purposes, the value of the constant, $B$, should be rounded to 0.20 to give the following simplified spill plume formula described by Equation 19.

$$
M_{p}-M_{b}=0.20 Q^{1 / 3} W^{2 / 3}\left(z_{d}+d_{b}\right)
$$

Equation 19 can simply be rearranged to express the total mass flow rate of gases produced by a spill plume ( $M_{p}$ ) given by Equation 20 .

$$
M_{p}=0.20 Q^{1 / 3} W^{2 / 3}\left(z_{d}+d_{b}\right)+M_{b}
$$

Equation 20 is therefore proposed as a simplified spill plume formula to predict the entrainment of air into a balcony spill plume, which inherently includes entrainment of air into the free ends of the plume. Equation 20 applies to a spill plume which remains approximately two-dimensional in nature over the height of rise, with the limit given by Equation 21.

$$
\frac{Z}{W}<2
$$

A value of $B=0.20$, results in a value of $C_{m}=0.56$ [from Equation 11a]. However, this value inherently includes entrainment of air into the free ends. For a spill plume without entrainment into the free ends, Poreh et al [5] gives $C_{m}=0.44$. Comparison with the work by Poreh et al [5] shows that the constant, $B$, has increased from 0.16 (for no entrainment of air into the ends) to 0.20 in this work. For the conditions studied, the results indicate that for identical approach flow conditions at a spill edge, the entrainment of air into a balcony spill plume is increased by approximately $25 \%$ due to entrainment of air into the free ends. This compares well with the limited data from Marshall and Harrison [18] which indicated an increase in entrainment of approximately 30\%. A reanalysis of Marshall and Harrison's limited data (Series I), which included air entrainment into the ends of a balcony spill plume was carried out. The constant, $B$, was determined to be approximately 0.25 from this data. However, as this work was carried out within a small area smoke reservoir with additional entrainment occurring due to turbulence within the collecting hood, the constant, $B$ would be expected to be high in this case. Analysis of the data given by Hansell et al [14] gave rise to a value of $B=0.36$ (see Figure 9). However, this value of $B$ would also be expected to be high as this work was carried out within a relatively tall and narrow smoke reservoir. The spill plume also had a tendency to become more axisymmetric in nature due to the asymmetry of the inlets causing a swirling of the air below the main layer. 


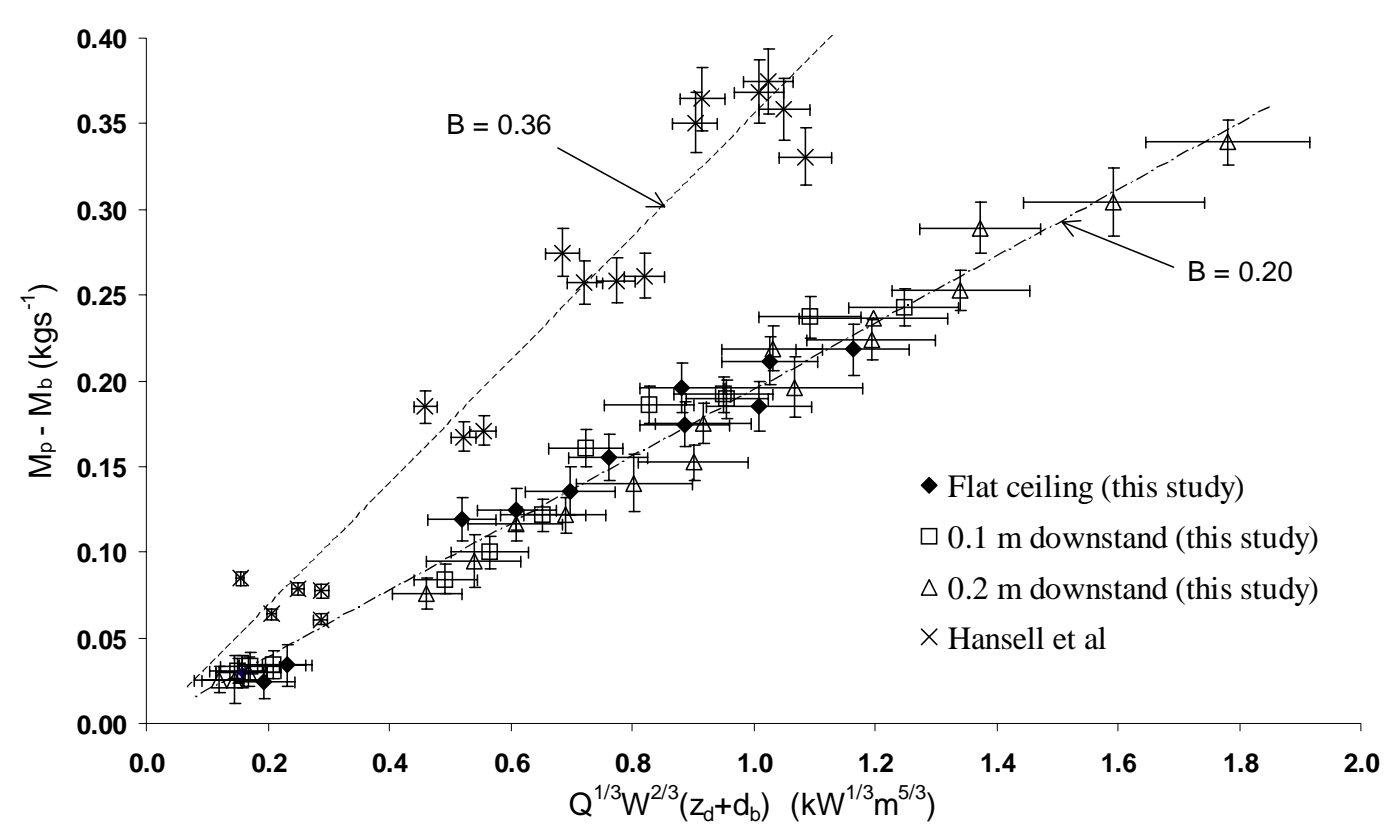

Figure 9: Comparsion of $\left(M_{p}-M_{b}\right)$ with respect to $Q^{1 / 3} W^{2 / 3}\left(z_{d}+d_{b}\right)$ between the data from this study and that from Hansell et al [14]

It is encouraging that the value of $B$ determined in this work is bounded by values which can be considered to be limiting. Equation 20 can be expressed in an alternative form using a method developed by Thomas et al [6] to remove an element of redundancy which requires the calculation of both $M_{b}$ and $d_{b}$. This gives rise to Equation 22 which can be considered to be an acceptable alternative to Equation 20.

$$
M_{p}=0.20 Q^{1 / 3} W^{2 / 3} Z+0.0017 Q+1.5 M_{b}
$$

It should be noted that $M_{b}$ can be calculated using methods given either by Morgan [10] or Thomas et al [20] (also used by Quintiere et al [25]) [see Appendix].

\section{Mass flow rate of gases without entrainment into the ends}

In an attempt to confirm that the experimental results were consistent with previous work, a test was carried out with a balcony spill plume without entrainment of air into the ends. This test generated a balcony spill plume identical to that examined by Poreh et al [5]. The results from this test were used to determine the value of the constant, $B$, within Equation 12. The results gave rise to a value of $B=0.167$, which was consistent with that determined by Poreh et al (i.e. $B=0.16$ ). 


\section{Comparison of the experiment with the BRE spill plume method}

The experimental results were compared with the prediction made by the BRE spill plume method [1] for the mass flow rate of gases produced by a balcony spill plume, with respect to the height of rise above the spill edge. The input parameters used in the BRE method were the mass flow rate $\left(M_{b}\right)$ and convective heat flux of the gases at the spill edge $(Q)$ for all of the tests. Comparisons were made for those tests which either had a flat ceiling or a downstand at the spill edge. The BRE spill plume method prediction is presented in the following forms:

- Using an entrainment constant, $\alpha$, equal to 0.16 , with no adjustment to the height of rise of the plume

- Applying the effective layer depth correction to adjust the height rise of the plume to take into account the smoke reservoir geometry

- Using an entrainment constant, $\alpha$, equal to 0.11 , with no adjustment to the height of rise of the plume. This value of $\alpha$ was demonstrated by Poreh et al [5] to give good agreement with experimental results for a balcony spill plume without entrainment of air into the ends, for a large area reservoir

Figure 10 shows a comparison between the experimental results and the predictions for the mass flow rate of gases produced by a balcony spill plume, with respect to the height of rise above the spill edge, for those tests with $Q_{T}=6 \mathrm{~kW}(Q=4.9 \mathrm{~kW})$ and a flat ceiling at the spill edge. Figure 10 also shows the line describing Equation 22 which was determined using the experimental value of $M_{b}$. Figure 10 shows that when the BRE method is used with $\alpha=0.16$, with no adjustment to the height of rise, the method over predicts the mass flow rate of gases due to a spill plume. This indicates that the smoke exhaust hood could be considered to be a large area reservoir, such that an adjustment to the height of rise, or the entrainment constant, is required for the prediction to match with the experiment. However, this conclusion contradicts the classification criteria for smoke reservoir geometry given by Morgan et al [1], which suggests that the exhaust hood can be considered to be a small area reservoir. The results suggest that the classification criteria may not be reliable for all scenarios and should be used with caution. The results confirm that further work is necessary to examine the difference in entrainment between large and small area smoke reservoirs.

Figure 10 shows that when the effective layer depth correction is applied to the visual layer depth, the BRE method under predicts the experimental results. The prediction was only possible for two data points, since the correction resulted in a negative height of rise in some cases. The effective layer depth correction was derived from empirical data to achieve a match between the BRE method and the experimental results for large area reservoirs [8]. However, this correction was developed from experimental data in which there was warming of the air beneath the visual layer base in the reservoir. In this experiment, there was no warming of the air nominally beneath the visible smoke layer. The results suggest that the effective layer depth correction may not be reliable when applied to conditions which are dissimilar to that in which the method was derived. 


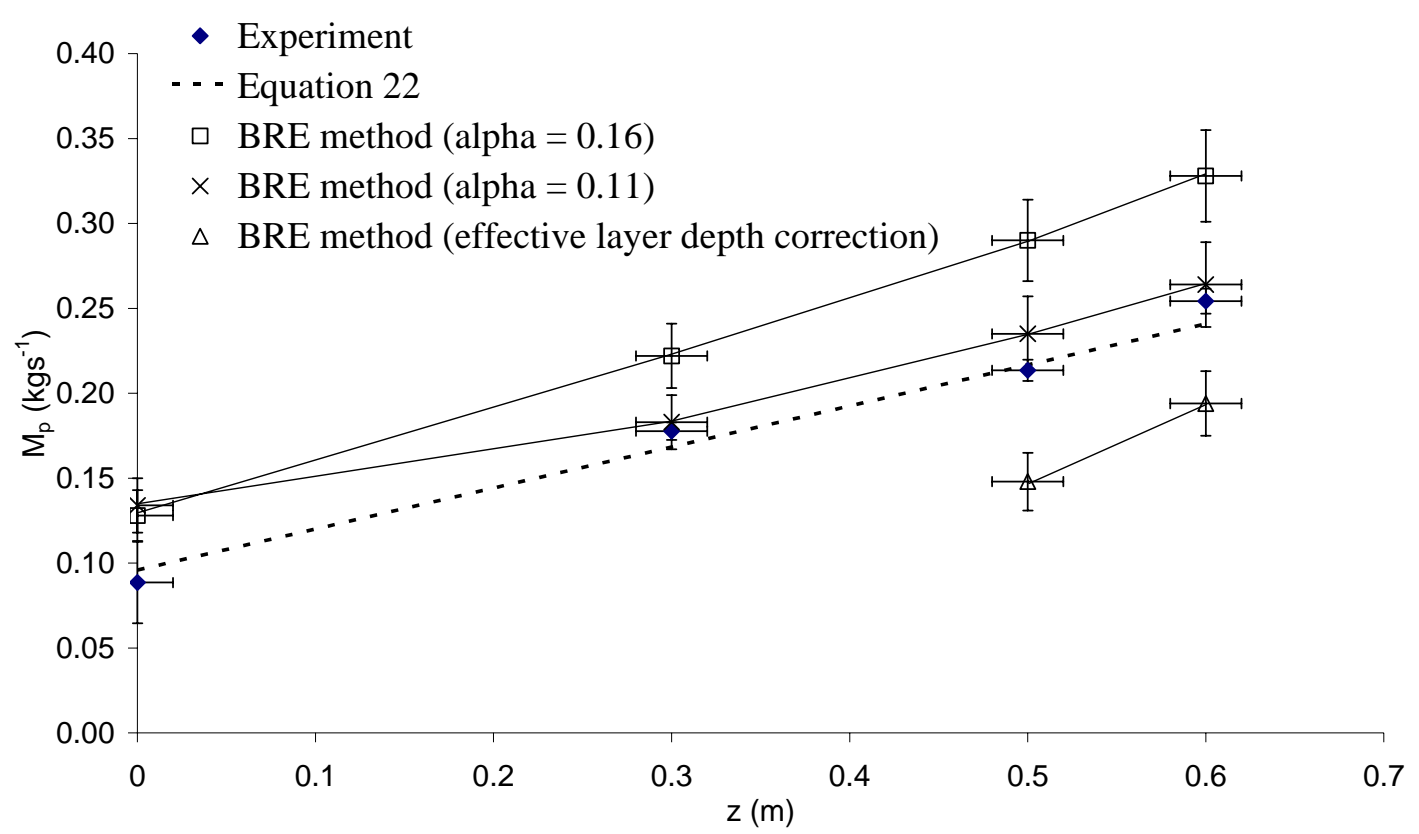

Figure 10: Comparison between experiment and the BRE method $\left(Q_{T}=6 \mathrm{~kW}, Q=4.9 \mathrm{~kW}\right.$, flat ceiling)

Figure 10 shows that when the BRE method is used with $\alpha=0.11$, with no adjustment to the height of rise, the method gives a good match with the experimental results above a height of rise of $0.3 \mathrm{~m}$ above the spill edge. There is an expected discrepancy between the experiment and the prediction when the height of rise is zero, as one of the fundamental assumptions in the underpinning theory (e.g. Gaussian profiles across the plume) is violated in this region. It is encouraging to note that the slope of the line relating the mass flow rate of gases with respect to the height of rise is similar between the prediction and the experimental results. This indicates that the BRE method accurately predicts the increase in entrainment with respect to the height of rise of the plume. The above result indicates that, for large area reservoirs, it may be more reliable to apply the BRE method with a reduced entrainment constant of 0.11 rather than adjusting the height of rise of the plume.

For those tests with a fire size of $Q_{T}=9 \mathrm{~kW}(Q=7.4 \mathrm{~kW})$ and $Q_{T}=12 \mathrm{~kW}(Q=$ $10.4 \mathrm{~kW})$, the comparisons generally show a similar behaviour to that described above, however, the agreement between the experiment and the prediction using $\alpha=$ 0.11 tended to increase with increasing fire size. This discrepancy may be due to inaccuracies in the term quantifying the entrainment of air into the ends of the plume for the larger fire sizes. However, the slope of the line relating the mass flow rate gases with respect to the height of rise of the plume was similar between the experimental results and the prediction when $\alpha=0.11$.

Figure 11 shows a comparison between the experimental results and the prediction for the mass flow rate of gases due to a spill plume, with respect to the height of rise of the plume, for those tests with a fire size of $Q_{T}=6 \mathrm{~kW}(Q=4.3 \mathrm{~kW})$ and a $0.1 \mathrm{~m}$ downstand at the spill edge. 


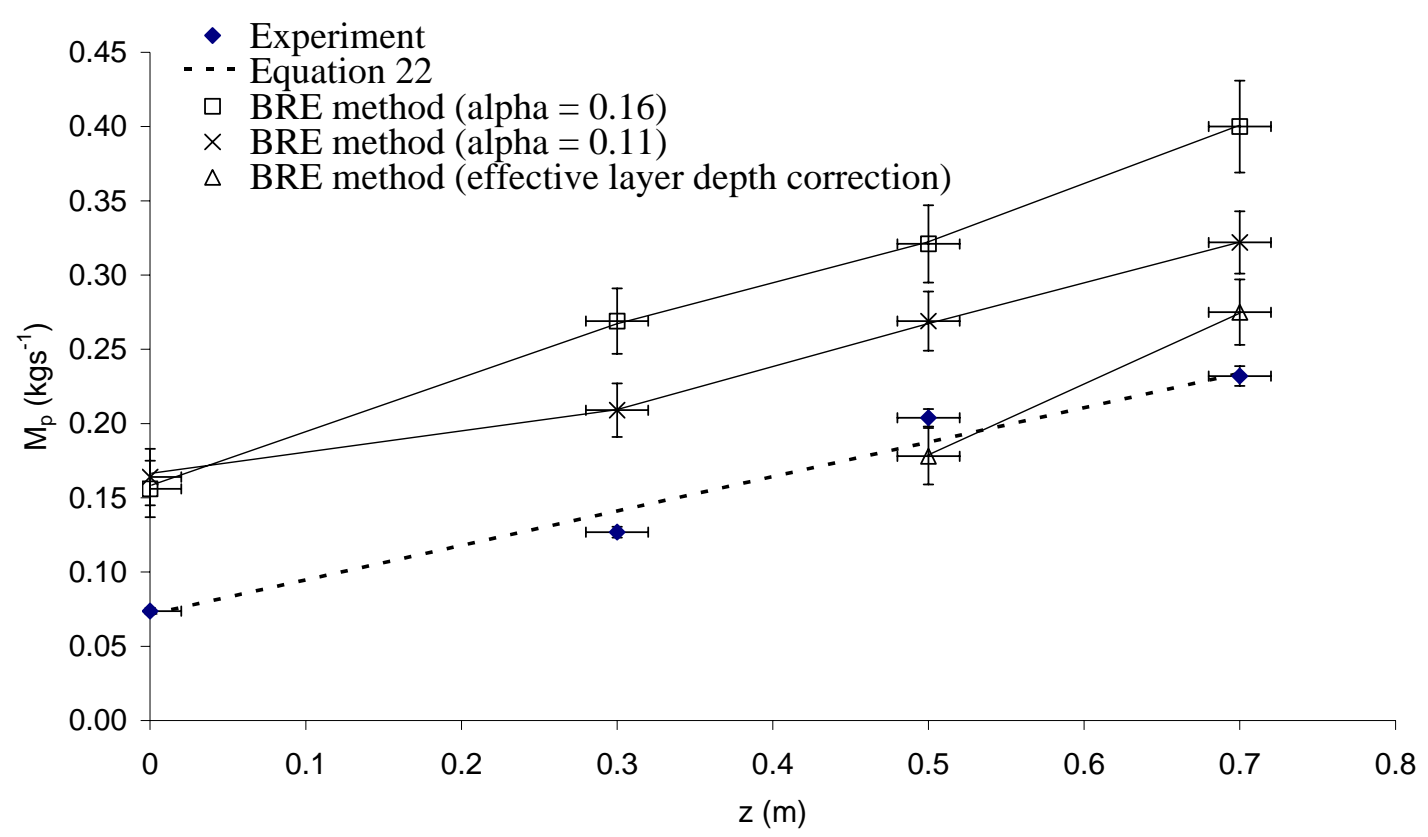

Figure 11: Comparison between experiment and the $B R E \operatorname{method}\left(Q_{T}=6 \mathrm{~kW}, Q=4.3 \mathrm{~kW}, 0.1 \mathrm{~m}\right.$ downstand)

Figure 11 shows that when the BRE method is used with either $\alpha=0.16$ or $\alpha=0.11$, with no adjustment to the height of rise, the method over predicts the mass flow rate of gases due to a spill plume. It is unclear why the presence of downstand has worsened the agreement between the experiment and the prediction (with $\alpha=0.11$ ) compared to those tests with a flat ceiling. This may be due to differences in the characteristics of the horizontal approach flow at the spill edge on the subsequent spill plume prediction. This discrepancy could also be due to the fact that a $0.1 \mathrm{~m}$ downstand may not be considered to be a "deep" downstand, as assumed in the BRE method. The slope of the line relating the mass flow rate of gases with respect to the height of rise of the plume is again similar between the experimental results and the prediction when $\alpha=0.11$. Figure 11 shows that when the effective layer depth correction is applied, the BRE method gives a reasonable match with the experimental results, although it appears that there may be divergence between experiment and the prediction at higher heights of rise. Since there are only two data points for the prediction, the comparison is inconclusive. For those tests with a fire size of $Q_{T}=$ $9 \mathrm{~kW}(Q=6.3 \mathrm{~kW})$ and $Q_{T}=12 \mathrm{~kW}(Q=9.1 \mathrm{~kW})$ the comparisons generally show a similar behaviour to that described by Figure 11.

Figure 12 shows a comparison between the experimental results and the prediction for the mass flow rate of gases due to a spill plume, with respect to the height of rise above the spill edge, for those tests with a fire size of $Q_{T}=6 \mathrm{~kW}(Q=4.1 \mathrm{~kW})$ and a $0.2 \mathrm{~m}$ downstand at the spill edge. Figure 12 shows that when the BRE method is used with either $\alpha=0.16$ or $\alpha=0.11$, with no adjustment to the height of rise, the method again over predicts the mass flow rate of gases due to a spill plume. As noted above, the slope of the line relating the mass flow rate gases with respect to the height of rise of the plume is again similar between the experimental results and the prediction when $\alpha=0.11$. Figure 12 shows that when the effective layer depth correction is applied, there is divergence between experiment and the prediction which increases at higher heights of rise. 


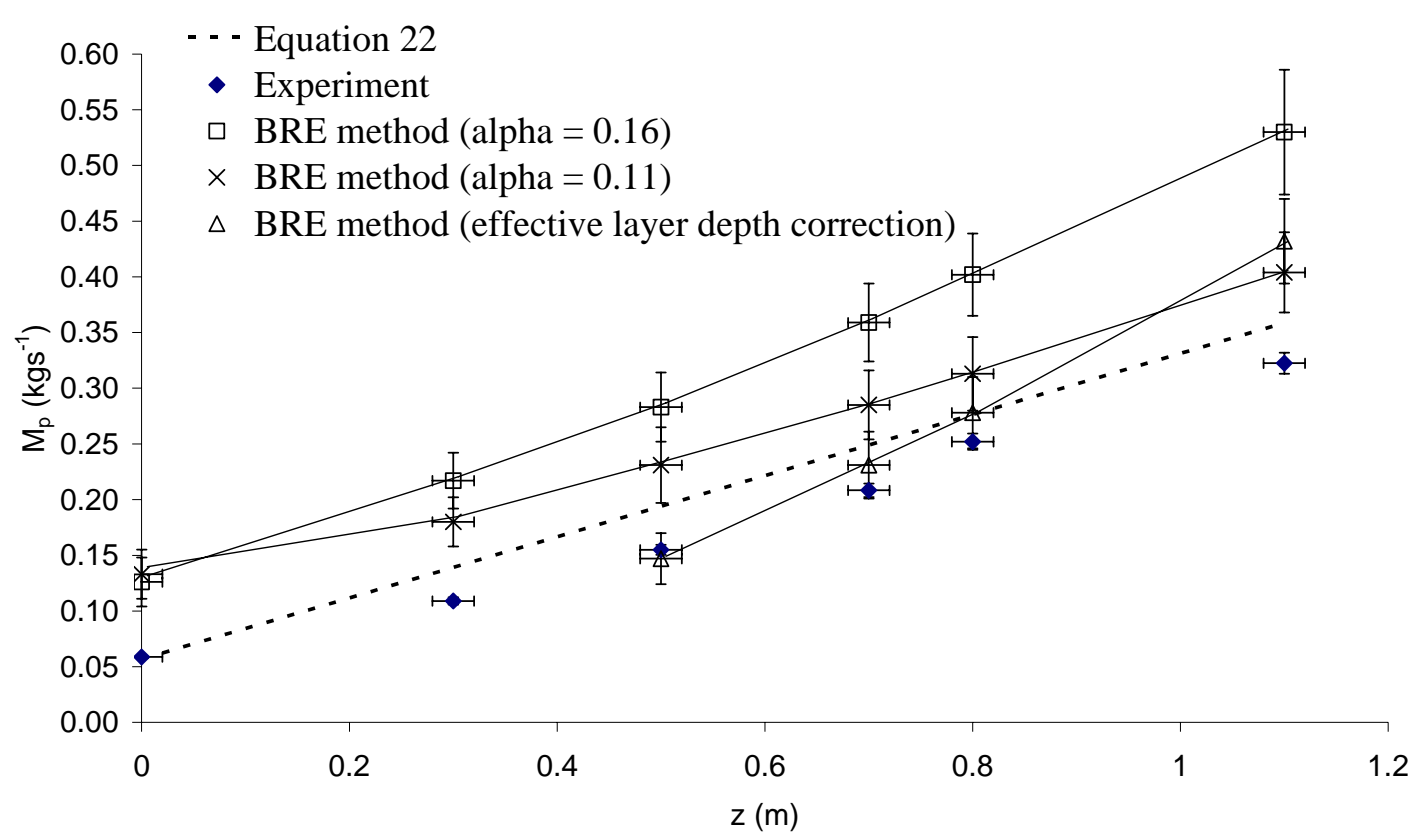

Figure 12 : Comparison between experiment and the $B R E \operatorname{method}\left(Q_{T}=6 \mathrm{~kW}, Q=4.1 \mathrm{~kW}, 0.2 \mathrm{~m}\right.$ downstand)

For those tests with a fire size of $Q_{T}=9 \mathrm{~kW}(Q=6.3 \mathrm{~kW})$ and $Q_{T}=12 \mathrm{~kW}(Q=$ $8.7 \mathrm{~kW}$ ) the comparisons generally show a similar behaviour to that described by Figure 12.

\section{Comparison of the experiment with various simplified spill plume formulae}

Comparisons were also made between the experimental results and predictions made from various simplified spill plume formulae. Comparisons were only made for those tests which had a flat ceiling at the spill edge as these formulae do not apply to flows which have a downstand at the spill edge. The following spill plume formulae, which include entrainment into the free ends, were examined for the comparison.

- Method by Law (1986) [Equation 4].

- Method by Law (1995) [Equation 5].

- Method by Thomas (1987), [Equation 8]. The location of the virtual source $\left(z_{0}\right)$ was determined using an explicit formula given by Poreh et al [5], giving $0.372 \mathrm{~m}, 0.386 \mathrm{~m}$ and $0.392 \mathrm{~m}$ for $Q_{T}=6,9$ and $12 \mathrm{~kW}$ respectively.

- Method given by CIBSE [Equation 6].

- Method given in NFPA 92B [Equation 9].

The value of $h_{\text {comp }}$ was taken to be $0.5 \mathrm{~m}$ as in the experiment. 


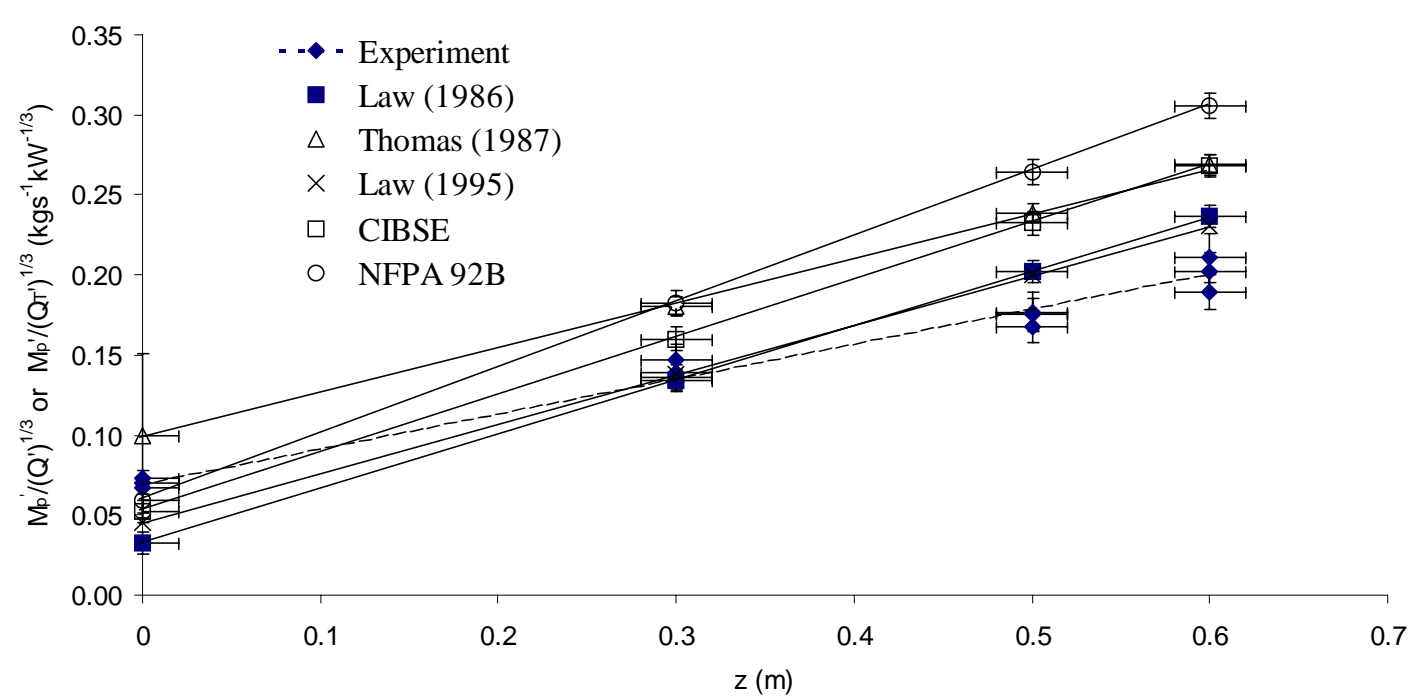

Figure 13: Comparison between the experiment and simplified spill plume formulae

Figure 13 shows a comparison of the various simplified formulae for all of the fire sizes examined by plotting $\frac{M_{p}^{\prime}}{\left(Q_{T}^{\prime}\right)^{1 / 3}}$ with respect to $z$ for the methods by Law and Thomas, and $\frac{M_{p}^{\prime}}{\left(Q^{\prime}\right)^{1 / 3}}$ with respect to $z$ for the CIBSE and NFPA 92B methods.

Figure 13 shows that, with the exception of the method by Thomas [4], all of the simplified formulae under-predict the mass flow rate due to a spill plume at a very low height of rise. However, above a height of rise of approximately $0.3 \mathrm{~m}$ (3 m full scale), all of the methods generally tend to over predict the mass flow rate of gases due to a balcony spill plume. The slope of the line relating the mass flow rate gases with respect to the height of rise of the plume, is generally greater for the various simplified formulae compared to the experiment. The comparison indicates that the discrepancy between the experiment and the predictions will increase as the height of rise increases. The method given in NFPA 92B [17] significantly over predicts the mass flow rate of gases due to spill plume. However, this is not surprising as this method has been modified to make the calculated entrainment approach that for an axisymmetric plume at large heights of rise. The method by Thomas [4] may give improved agreement with the experiment with if an alternative location of the virtual source is assumed. 


\section{CONCLUSIONS}

This work has addressed various limitations and uncertainties in current calculation methods for the spill plume in smoke ventilation design. The conclusions and findings from this work are described below.

1. The entrainment of air into the spill plume appears to be the same, whether the spill edge is at the downstand edge or at the balcony edge.

2. The presence of a deep downstand at the spill edge caused the emerging plume to rise vertically from the opening. This behaviour has significant implications for smoke logging on higher storeys due to partial impingement of the plume with balconies above.

3. A simplified spill plume formula has been determined to predict the mass flow rate of gases due to a balcony spill plume. This formula is given by:

$$
M_{p}=0.20 Q^{1 / 3} W^{2 / 3}\left(z+d_{b}\right)+M_{b}
$$

This formula inherently includes entrainment of air into the free ends of the plume and applies to approach flows which have a flat ceiling or a downstand at the spill edge. This equation applies to large area smoke reservoirs. An acceptable alternative to this formula is given by,

$$
M_{p}=0.20 Q^{1 / 3} W^{2 / 3} Z+0.0017 Q+1.5 M_{b}
$$

These formulae only apply to 'large' area smoke reservoirs for design conditions which obey the following limit.

$$
\frac{Z}{W}<2
$$

4. The results indicate that the value of $C_{m}$ was approximately equal to 0.56 . This value inherently includes entrainment of air into the free ends.

5. For the conditions studied, the results indicate that for identical approach flow conditions at a spill edge, the entrainment of air into a balcony spill plume is increased by approximately $25 \%$ due to entrainment of air into the free ends.

6. For a flat ceiling at the spill edge, the BRE spill plume method gave reasonably good agreement with the experimental results when used with an entrainment constant, $\alpha=0.11$, with no adjustment to the height of rise of the plume. The agreement worsened with increasing fire size, which may be due to inaccuracies in the term to predict the entrainment of air into the free ends. The use of the effective layer depth correction (without adjusting $\alpha$ ) did not provide good agreement with the experimental results. This suggests that the effective layer depth correction may not be reliable when applied to conditions which are dissimilar to that in which the method was derived. The above result indicates that, for large area reservoirs, it may be more reliable to apply the BRE method 
using an entrainment constant, $\alpha=0.11$, rather than adjusting the height of rise of the plume. When a downstand was present at the spill edge, the BRE spill plume method did not generally give good agreement with the experimental results. However, the predicted results were conservative.

7. The classification criteria between 'large' and 'small' area smoke reservoirs given by Morgan et al [1] may not be reliable for all scenarios and should be used with caution.

8. Comparison of predictions from various simplified spill plume formulae with the experimental results, indicated that these methods tended to under predict the mass flow rate of gases at low heights of rise, whilst over predicting at higher heights of rise above the spill edge (above $3 \mathrm{~m}$ full scale).

\section{ACKNOWLEDGEMENTS}

The authors would like to thank the following: The Society of Fire Protection Engineers Educational and Scientific Foundation, for providing funding for this research. FRS, for allowing the primary author to undertake an 18 month sabbatical to complete this research. Russell Peoples and Grant Dunlop, of the University of Canterbury, for their invaluable help with the design and construction of the experimental apparatus. NV IFSET SA, for permission to reproduce Figure 1.

\section{NOMENCLATURE}

\section{Symbol}

A

B

$C_{m}$

$c_{p}$

$C_{d}$

$d$

$g$

h

L

$M$

$\delta m$

$Q$

$Q_{T}$

$T$

$u$

V

W

Z

$Z_{0}$

\section{Description}

Area $\left(\mathrm{m}^{2}\right)$

A constant given in Equation $9\left(\mathrm{kgm}^{1 / 3} \mathrm{~s}^{-1} \mathrm{~kW}^{-1 / 3}\right)$

Dimensionless entrainment coefficient

Specific heat $\left(\mathrm{Jkg}^{-1} \mathrm{~K}^{-1}\right)$

Coefficient of discharge

Depth (m)

Acceleration due to gravity $\left(\mathrm{ms}^{-2}\right)$

Height above floor (m)

Characteristic linear height of the model

Mass flow rate of gases $\left(\mathrm{kgs}^{-1}\right)$

Mass flow rate of air entrained on rotation $\left(\mathrm{kgs}^{-1}\right)$

Convective heat flux at the spill edge (kW)

Total heat output of fire $(\mathrm{kW})$

Absolute gas temperature (K)

Velocity $\left(\mathrm{ms}^{-1}\right)$

Volume flow rate $\left(\mathrm{m}^{3} \mathrm{~s}^{-1}\right)$

Lateral extent of gas flow spill edge (m)

Height of rise of plume from the balcony spill edge to the smoke layer base in the reservoir (m)

Height of virtual line source below the spill edge (m) 
$Z_{d}$

\section{Greek symbol}

$\alpha$
$\alpha$
$\theta$
$\rho$
$\kappa_{M}$
$\tau$

\section{List of subscripts}

1

$a$

air

$b$

$c$

e

comp

$p$

$v$

$w$

$y$

Height of rise of the plume from the spill edge of a downstand to the smoke layer base in the reservoir (m)

\section{Description}

Entrainment constant for plume

Entrainment constant for air mixing into gases rotating round a horizontal edge

Excess temperature of gases above ambient temperature $\left({ }^{\circ} \mathrm{C}\right)$

Density $\left(\mathrm{kgm}^{-3}\right)$

Profile correction factor for mass flow (approx 1.3)

The time scale

\section{Description}

An ambient property

Variable evaluated in atrium or smoke reservoir

A property of air

Variable evaluated in the horizontal layer flow at the spill edge

Variable evaluated at highest point in a flow

An effective property of the smoke layer

A property of the fire compartment

Variable evaluated in the plume at an arbitrary height of rise

A visual property of the smoke layer

Variable evaluated in the horizontal layer flow at the compartment opening

Variable evaluated in a vertical flow past the top of the opening

\section{REFERENCES}

1. Morgan H P, Ghosh B K, Garrad G, Pamlitschka R, De Smedt J-C and Schoonbaert L R., "Design methodologies for smoke and heat exhaust ventilation”, BRE Report 368, 1999.

2. Harrison R. "Smoke control in atrium buildings: A study of the thermal spill plume”, Fire Engineering Research Report 04/1, Department of Civil Engineering, University of Canterbury, New Zealand, 2004.

3. Law M. “A note on smoke plumes from fires in multi-level shopping malls”, Fire Safety Journal, 10, pp 197-202, 1986.

4. Thomas P H. "On the upward movement of smoke and related shopping mall problems”, Fire Safety Journal, 12, pp 191-203, 1987.

5. Poreh M, Morgan H P, Marshall N R and Harrison R., "Entrainment by two dimensional spill plumes in malls and atria”, Fire Safety Journal, 30, pp 1-19, 1998.

6. Thomas P H, Morgan H P and Marshall N R., "The spill plume in smoke control design”, Fire Safety Journal, 30, pp 21-46, 1998.

7. Morgan H P and Marshall N R., "Smoke hazards in covered multi-level shopping malls: an experimentally-based theory for smoke production”, BRE Current Paper 48/75, BRE, 1975. 
8. Morgan H P and Marshall N R., "Smoke control measures in a covered twostorey shopping mall having balconies and pedestrian walk ways”. BRE Current paper 11/79, BRE, 1979.

9. Morgan H P and Hansell G O., "Atrium buildings: calculating smoke flows in atria for smoke control design”, Fire Safety Journal, 12, pp 9-35, 1987.

10. Morgan H P., "The horizontal flow of buoyant gases toward an opening”, Fire Safety Journal, 11, pp 193-200, 1986.

11. Miles S, Kumar S and Cox G., "The balcony spill plume - Some CFD simulations”, Fire Safety Science - Proceedings of the Fifth International Symposium, International Association of Fire Safety Science, pp 237-247, Melbourne, Australia.

12. Yii E H., "Exploratory salt water experiments of balcony spill plume using laser induced fluorescence technique”, Fire Engineering Research Report 98/7, Department of Civil Engineering,University of Canterbury, New Zealand, 1998.

13. Shao-Lin Lee and Emmons H W., "A study of natural convection above a line fire”, Journal of Fluid Mechanics, 11(3), pp 353-368, 1961.

14. Hansell G O, Morgan H P and Marshall N R., "Smoke flow experiments in a model atrium”, BRE Occasional Paper OP55, BRE, 1993.

15. Law M., "Measurements of balcony smoke flow”, Fire Safety Journal, 24, pp 189-195, 1995.

16. Chartered Institution of Building Services Engineers., CIBSE Guide Volume E: Fire Engineering, London, CIBSE, 2003.

17. National Fire Protection Association., "Smoke management systems in malls, atria and large areas”, 2000 Edition, Publication No.92B, Quincy MA, USA, NFPA, 2005.

18. Marshall N R and Harrison R., "Experimental studies of thermal spill plumes", Building Research Establishment Occasional Paper, OP1, 1996.

19. British Standards Institution., PD 7974: Application of fire safety engineering principles to the design of buildings. Part 2: Spread of smoke and toxic gases within and beyond the enclosure of origin. London, BSI, 2002.

20. Thomas P H, Hinkley P L, Theobald C R and Simms D L., "Investigations into the flow of hot gases in roof venting”, Fire Research Technical paper No 7, London, The Stationary Office, 1963.

21. Marshall N R., "The behaviour of hot gases flowing within a staircase”, Fire Safety Journal, 9, pp 245-255, 1985.

22. Quintiere, J. G. , Scaling Applications in Fire Research, Fire Safety Journal, Vol. 15, No. 1, pp. 3-29, 1989.

23. Klote J. H. and Milke, J. A., Chapter 15 Physical Modeling, Principles of Smoke management, ASHRAE, Atlanta, GA, 2002.

24. Morgan H P, Marshall N R and Goldstone B M., "Smoke hazards in covered multi-level shopping malls: some studies using a model 2-storey mall”, Building Research Establishment Current Paper, CP45/76, BRE, 1976.

25. Quintiere J G, McCaffrey B J and Rinkinen W J, "Visualisation of room fireinduced smoke movement and flow in a corridor”, Fire and Materials, 2 (1), 1978. 


\section{APPENDIX}

The mass flow rate of gases at the gases at the spill edge $\left(M_{b}\right)$ can be calculated using methods given either by Morgan (10) [Equation A.1] or Thomas et al (20) [Equation A.2]. This Appendix shows a comparison of the experimental results with the predictions made using these methods.

$$
\begin{aligned}
& M_{b}=\frac{2}{3} C_{d}^{3 / 2}\left(2 g \theta_{c, w} T_{1}\right)^{1 / 2} \frac{W \rho_{1}}{T_{c, w}} d_{w}^{3 / 2} \kappa_{M} \\
& M_{b}=\frac{2}{3} C_{d}\left(2 g \theta_{c, w} T_{1}\right)^{1 / 2} \frac{W \rho_{1}}{T_{c, w}} d_{w}^{3 / 2}
\end{aligned}
$$

Figure A.1 shows a comparison of the predictions with the experimental results for those tests with a flat ceiling at the spill edge (for $\mathrm{Q}_{\mathrm{T}}=6,9$ and $12 \mathrm{~kW}$ respectively). The predictions were made assuming $C_{d}=1.0$ for the opening at the spill edge. Figure A.1 shows that the method given by Morgan (10) gives excellent agreement with the experiment for all of the tests. The method by Thomas et al (20) gives a prediction approximately $25 \%$ lower for this condition. However, this method is recognised to be applicable to wide compartment openings with a deep downstand.

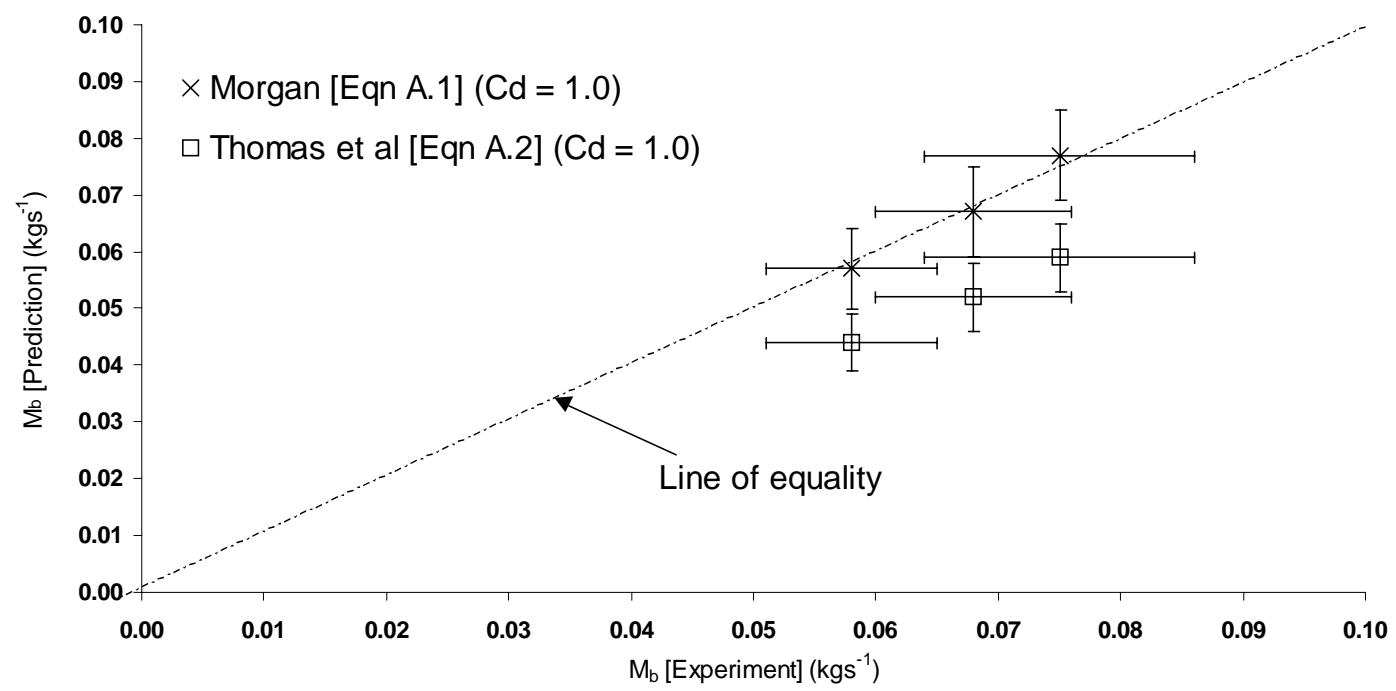

Figure A.1: Comparison of the predictions of $M_{b}$ with the experiment for those tests with a flat ceiling at the spill edge 
Figure A.2 shows a comparison of the predictions with the experimental results for those tests with a downstand ( 0.1 and $0.2 \mathrm{~m}$ deep) at the spill edge (for $\mathrm{Q}_{\mathrm{T}}=6,9$ and $12 \mathrm{~kW}$ respectively). The predictions were made assuming $\mathrm{C}_{\mathrm{d}}=0.6$ to take into account the presence of a downstand at the spill edge. Figure A.2 shows that the methods given by Morgan (10) and Thomas et al (20) are equivalent in this case. However, they both under predict the experimental results by approximately $30 \%$ for this condition. This discrepancy may be due to these methods being applicable for openings which have the same width as the compartment. However, in this work, the opening was restricted (i.e. the width of opening was significantly less than the width of the compartment). A value of $\mathrm{C}_{d}=0.8$ provides much improved agreement between the prediction and experiment for this condition, particularly for the method given by Morgan (10). This work has highlighted that further work is desirable to determine appropriate values of $C_{d}$ for different compartment opening geometries (e.g restricted or narrow compartment openings).

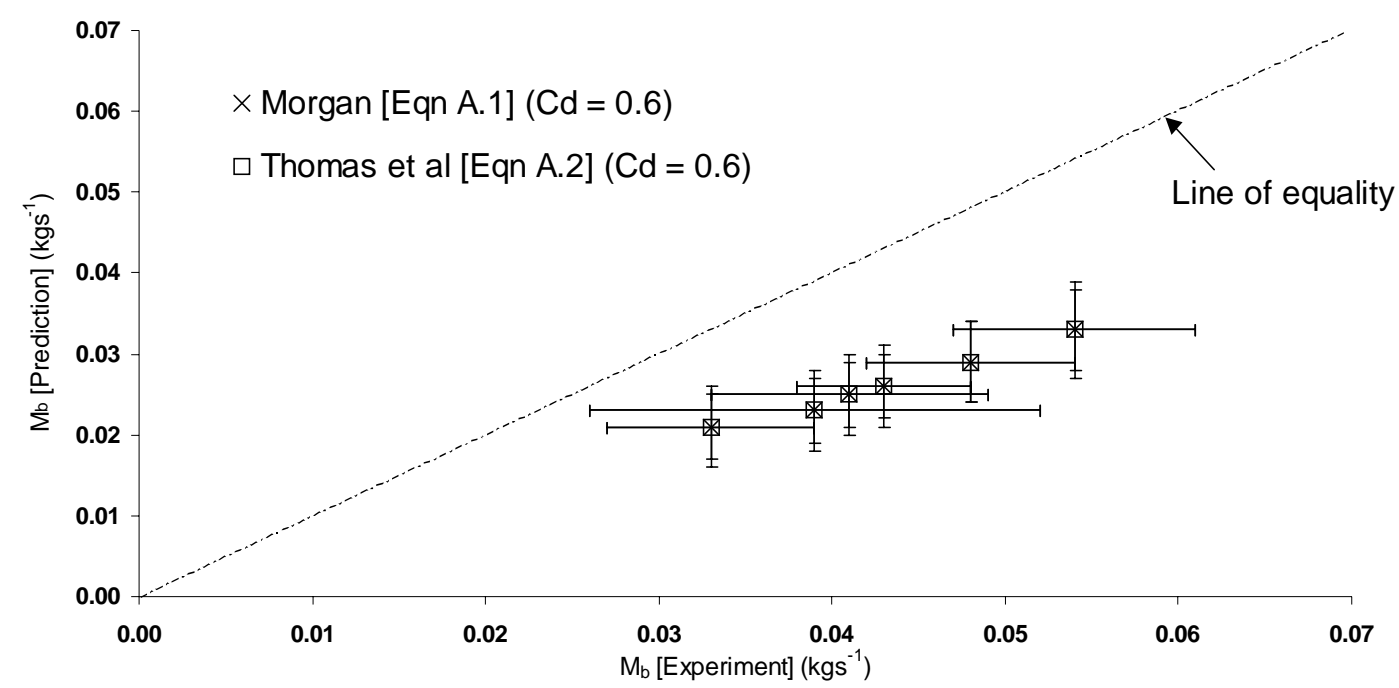

Figure A.2: Comparison of the predictions of $M_{b}$ with the experiment for those tests with a downstand at the spill edge 